\title{
Thermodynamics and the Glass Forming Ability of Alloys
}

\author{
Chengying Tang and Huaiying Zhou \\ Guilin University of Electronic Technology \\ P. R. China
}

\section{Introduction}

Bulk metallic glasses (BMGs) have received a great deal of attention due to scientific and technological interest ever since the first successful synthesis of an amorphous phase in the Au-Si system in 1960 (Klement et al., 1960). There has been a lot of interest to identify parameters to assess the glass forming ability (GFA) of various alloy systems and compositions. A great deal of scientific efforts for quantification of GFA of alloys has been devoted to investigation of the GFA of alloys. There have been a lot of parameters to assess the glass forming ability (GFA) of various alloy systems and compositions. As a result, many criteria, including the confusion rule and the deep eutectic rule, for evaluating the glass forming ability (GFA) of an amorphous alloy have been proposed. Among them, the criteria used usually are the supercooled liquid region $\Delta T_{x}\left(=T_{x}-T_{g}\right.$, where $T_{g}$ and $T_{x}$ are the glass transition temperature and the crystallization temperature, respectively) (Inoue et al., 1993), the reduced glass transition temperature $T_{r g}\left(=T_{g} / T_{l}\right.$, where $T_{l}$ is the liquidus temperature) (Turnbull, 1969) and the recently defined parameters $\gamma\left(=T_{x} /\left(T_{g}+T_{l}\right)\right)$ (Lu \& Liu, 2002), $\delta\left(=\mathrm{T}_{x} /\left(\mathrm{T}_{l}-\mathrm{T}_{g}\right)\right) \quad$ (Chen, et al., 2005), $\beta\left[=\mathrm{T}_{x} \mathrm{~T}_{g} /\left(\mathrm{T}_{l}+\mathrm{T}_{x}\right)^{2}\right] \quad$ (Yuan, et al., 2008), $\phi\left(=\Delta T_{\mathrm{rg}}\left(T_{x} / T_{\mathrm{g}}\right)^{0.143}\right)$ (Fan, et al. 2007), $\omega\left[=\mathrm{T}_{l}\left(\mathrm{~T}_{l}+\mathrm{T}_{x}\right) /\left(\mathrm{T}_{x}\left(\mathrm{~T}_{l}-\mathrm{T}_{x}\right)\right)\right]$ (Ji \& Pan, 2009), $\gamma_{c}\left[=\left(3 T_{x^{-}}\right.\right.$ $\left.2 \mathrm{~T}_{\mathrm{g}}\right) / \mathrm{T}_{l}$ ) (Guo, 2010), and so on. These criteria have generally proved useful parameters for evaluating the GFA of an amorphous alloy. In order to guide the design of alloy compositions with high GFA, Inoue et al. (Inoue et al., 1998) and Johnson (Johnson, 1999) have proposed the following empirical rules: (I) multicomponent systems, (II) significant atomic size ratios above $12 \%$, (III) negative heat of mixing and (IV) deep eutectic rule based on the $\mathrm{T}_{\mathrm{rg}}$ criterion. However, Al-based metallic glasses with rare earth metal additions (Guo et al., 2000), rare earth (RE) based glasses and some binary BMGs such as $\mathrm{Zr}-\mathrm{Cu}$, Ni$\mathrm{Nb}$ binary alloy (Xia et al., 2006), provide important exception from this generality, because most of above mentioned GFA parameters and rules capable of searching metallic glasses with high GFA are not applicable to these Al-based and RE-based amorphous systems. Furthermore, all the above parameters need the alloy to be first prepared in glassy form to be able to measure the crystallization temperature $T_{x}$, the liquidus temperature $T_{l}$, and/or the glass transition temperature $\mathrm{T}_{8}$. Hence, the above parameters are not predictive in nature, as they cannot predict a good glass forming composition without actually making that alloy and rapidly solidifying it into the glassy state. It is well known that crystallization is the only event that prevents the formation of an amorphous phase. Metallic glass formation is always a competing process between the undercooled melt and the resulting 
crystalline phases. The GFA of a melt is thus virtually determined by the stability of the undercooled melt and the competing crystalline phases. Thermodynamic analysis could be useful in evaluating the stability of the undercooled melt and the formation enthalpies of crystalline phases. So far, several attempts have been made successfully to investigate the GFA and predict glass forming range (GFR) in several binary and ternary amorphous alloy systems, using a pure thermodynamic approach or a combined thermodynamics and kinetics approach.

From a thermodynamic point of view, there are generally following methods for calculating the GFA and predicting glass forming range (GFR) of an alloy system. The first approach is based on the $T_{0}$ curve, which has been used to predict the GFR on several binary and some ternary systems. The quality of these predictions depends critically on the accuracy of the thermodynamic description. The second method is based on the semi-empirical Miedema's model, which has been successfully applied to calculate and predict the glass forming range of some binary or ternary systems. The third consideration is directly employed on the calculation of the driving forces of crystalline phases (minimum driving force criterion) in a supercooled melt using calculation of phase diagram (CALPHAD) database. By employing driving force criterion with the obtained thermodynamic description for the investigated system, the GFA and predicted GFR of an alloy system were determined by comparing the driving force of crystalline phases precipitated from an undercooled melt. This evaluation has been successfully used to evaluate the GFA of several binary or ternary systems. Especially, it can be used to analyze the GFA of some alloy systems with unique glass forming ability, such as Al-based system. The other thermodynamic considerations, such as suppression of the formation of intermetallic phases, have been introduced.

From a combined thermodynamics and kinetics approach, the GFA of the alloys were evaluated by introducing thermodynamic quantities obtained from CALPHAD method into Davies-Uhlmann kinetic formulations. In this evaluation, by assuming homogeneous nucleation without pre-existing nuclei and following the simplest treatment based on Johnson-Mehl-Avrami's isothermal transformation kinetics, the time-temperaturetransformation (TTT) curves were obtained, which are a measure of the time $t$ for formation of the phase $\Phi$ with a minimum detectable mass of crystal as a function of temperature. The critical cooling rates $\left(R_{c}\right)$ for the glass formation calculated on the basis of the TTT curves was used to evaluate the glass-forming ability of this binary or ternary alloy. The calculated GFA results show good agreement with the experimental data in the compositional glass formation range of the investigated systems.

This chapter is intended to present systematically the methods and progress on the glass forming ability investigated by a thermodynamic approach or a combined thermodynamics and kinetics approach.

\section{Calculation of GFA based on thermodynamics analysis}

Usually, it is regarded the formation of metallic glasses is controlled by two factors, i.e., the cooling rate and the composition of the alloy. The critical cooling, which is the most effective gauge for GFA of the alloys, is hard to be measured experimentally. Hence, a great deal of efforts has devoted to the investigation on the correlation between the GFA and the composition of glass forming alloys. Inoue et al. (Inoue et al., 1998) and Johnson (Johnson, 1999) proposed the empirical rules to predict the element selection and compositional range of glass forming alloy. These rules have played an important role as a guideline for synthesis of BMGs for the last decade. However, recent experimental results have shown that the "confuse 
principal" and "deep eutectic rule" cannot be applicable to the $\mathrm{Cu}-\mathrm{Zr}, \mathrm{Ni}-\mathrm{Nb}$ binary system (Xia et al., 2006) and Al-based ternary system (Guo et al., 2000). From a thermodynamic point of view, it is well known that crystallization is the only event that prevents the formation of an amorphous phase. During a melt-quenching process for metallic glass formation, the glass formation is exposed to crystallization competition of other crystalline phases from the undercooled melt between liquidus temperature $T_{1}$ and glass transition $T_{\mathrm{g}}$. The GFA of a melt is thus virtually determined by the stability of the undercooled melt and the competing crystalline phases, which can be analyzed by thermodynamic analysis. In this section, several GFA calculation based on thermodynamics analysis were introduced.

\subsection{Calculation of the GFA of alloys based on $\mathrm{T}_{0}$ curve}

\subsubsection{Method}

Generally, a glass can be formed during cooling when crystallization is avoided up to the occurrence of the glass transition. Thus, in order to predict the tendency to glass formation in a system and the composition regions where it is most probable, nucleation of crystals in the undercooled melt must be considered. The GFR will be the region of composition where nucleation of crystalline phases is less likely. Various models have been developed to analyze the GFA of alloys in the literature, as will be discussed in the following section, with different levels of approximation. $\mathrm{T}_{0}$ curve is one of the approaches used to estimate the GFA of the alloys.

$\mathrm{A} \mathrm{T}_{0}$ curve is the locus of the compositions and temperatures where the free energies of two phases are equal. Thus, $\mathrm{T}_{0}$ curves can be calculated provided that their Gibbs free energy is known, i.e. an assessment of the system is available. The $\mathrm{T}_{0}$ curve between the liquid and a solid phase determines the minimum undercooling of the liquid for the partitionless formation of a crystalline solid with the same composition (Boettinger \& Perepezko, 1993). Fig. 1 showed one example for a simple eutectic system. Alloys with $\mathrm{T}_{0}$ curves plunge steadily at low temperatures (dashed line in Fig. 1a), there will be no driving force for partitionless transformation in the composition region between them. If the equilibrium crystalline phases are not prone to nucleation, the glass can thus form. On the contrary, if $\mathrm{T}_{0}$ curves that are only slightly depressed below the stable liquidus curves are good candidate for partionless transformation of crystalline phases in the entire composition range (dashed line in Fig. 1b).

a

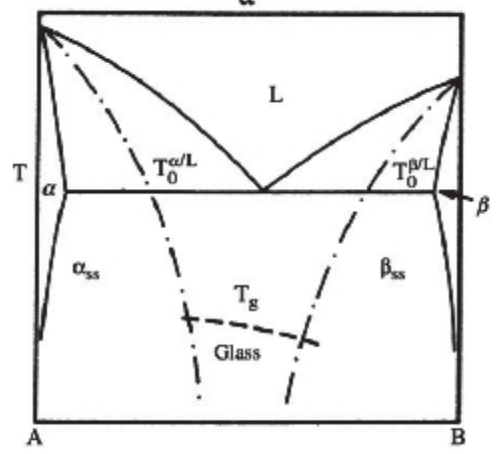

b

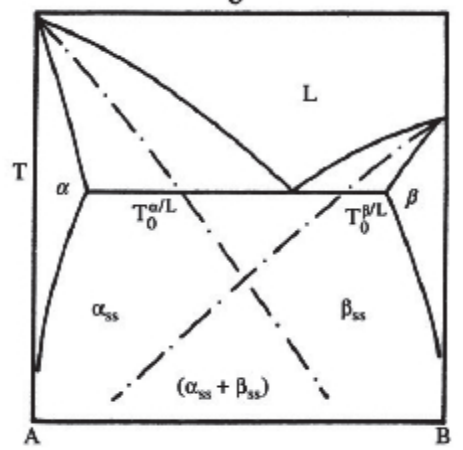

Fig. 1. Hypothetical $T_{0}$ curves for a binary eutectic A-B system. (a) $T_{0}$ curves drop to low temperature: glass formation is possible. (b) $T_{0}$ curves intersect at low temperature: partitionless crystalline phase formation occurs (redrawn from Boettinger \& Perepezko, 1993). 


\subsubsection{Application of $T_{0}$ curve}

Predictions of GFR based on $\mathrm{T}_{0}$ curves have been performed on several binary and some ternary systems. The construction of $\mathrm{T}_{0}$ curves for alloy glass needs a precise knowledge of thermodynamic properties of the supercooled liquid alloy and the introduction of the transition to the glassy state (Kim, et al., 1998). The quality of these predictions depends critically on the accuracy of the thermodynamic description and the introduction of the excess specific heat contribution is expected to improve the quality of results (Palumbo \& Battezzati, 2008). However, as pointed out by Schwarz and co-workers (Schwarz et al., 1987), some discrepancies have been observed between the prediction and experimental results. For example, even when using the most recent thermodynamic assessment (Kumar, 1996) to calculate $\mathrm{T}_{0}$ curves in the $\mathrm{Cu}-\mathrm{Ti}$ system, the results are not agreement with the reported experimental GFR. In fact, $\mathrm{T}_{0}$ curves for terminal solid solutions do not plunge at low temperatures as expected for glass forming systems (Kumar et al. 1996). Battezzati and co-workers (Battezzati, et al., 1990) have shown that in the $\mathrm{Cu}$-Ti system the contribution of the excess specific heat is essential for describing the glass forming ability. An excess specific heat contribution has also been considered in the Al-Ti system (Cocco, et al., 1990) and the Fe-B system (Palumbo, et al., 2001).

\subsection{Calculation of the GFA of alloys based on Miedema's model 2.2.1 Method}

Miedema's model is an empirical theory for calculating heat of mixing in various binary systems both for the solid state (Miedema et al., 1975) and liquid (Boom et al., 1976). This model involves the calculations of the formation enthalpy of metallic glasses (amorphous phase) $\left(\Delta H^{\mathrm{amor}}\right)$, solid solutions $\left(\Delta H^{\mathrm{SS}}\right)$, and intermetallic compounds ( $\left.\Delta H^{\text {inter }}\right)$ according to the following equations (Bakker 1988; Boer et al. 1988).

$$
\begin{gathered}
\Delta H^{\text {amor }}=\Delta H^{\text {chem }}(\text { amor })+\Delta H^{\text {topo }} \\
\Delta H^{s s}=\Delta H^{\text {chem }}(S S)+\Delta H^{\text {elastic }}+\Delta H^{\text {structure }}
\end{gathered}
$$

and

$$
\Delta H^{\text {inter }}=\Delta H^{\text {chem }}(\text { int er })
$$

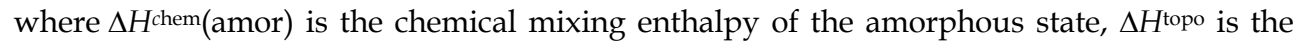
topology enthalpy of a glass, $\Delta H$ chem(SS) is the chemical mixing enthalpy of a solid solution, $\Delta H$ elastic is the elastic enthalpy of the solid solution calculated based on the continuous elastic model proposed by Friedel (Friedel, 1954) and Eshelby (Eshelby, $1954 \& 1956), \Delta H$ structure is the structure enthalpy induced by the structural changes, and $\Delta H$ chem(inter) is the chemical mixing enthalpy of an intermetallic compound. The formation enthalpy $\Delta H^{\text {inter }}$ of a composition between two adjacent intermetallic compounds can be calculated using the level principle.

The chemical contribution of enthalpy of mixing of solid solution can be written as

$$
\Delta H^{\text {chem }}=x_{A} x_{B}\left[x_{A} \Delta H_{B i n A}^{S S}+x_{B} \Delta H_{\text {Ain } B}^{S S}\right]
$$


where $x_{A}$ and $x_{B}$ represent the mole fraction of $\mathrm{A}$ and $\mathrm{B}$ atoms and $\Delta \mathrm{H}^{\mathrm{SS}}$ is the enthalpy of solution of one element in another at infinite dilution. The data have been taken from Niessen et al. (Niessen, et al., 1983).

The elastic term in the enthalpy of formation originates from the atomic size mismatch, which can be expressed as

$$
\Delta H^{\text {elastic }}=x_{A} x_{B}\left[x_{A} \Delta H_{B i n A}^{\text {elastic }}+x_{B} \Delta H_{\text {AinB }}^{\text {elastic }}\right]
$$

The $\Delta H_{\text {iinj }}^{\text {elastic }}$ has been obtained by using the formalism by Simozar and Alonso (Simozar \& Alonso, 1984) as

$$
\Delta H_{\text {iinj }}^{\text {elastic }}=\frac{2 \mu_{j}\left(V_{i}-V_{j}\right)^{2}}{V_{j}\left(3+4 \mu_{j} K_{i}\right)}
$$

where $\mu_{j}$ is the shear modulus of the solvent, $V_{i}$ and $V_{j}$ are the molar volumes of the solute and the solvent, respectively and $K_{i}$ is the compressibility of the solute.

The structural contribution of enthalpy for solid solution originates from the valence and the crystal structure of the solute and the solvent atom. It is found to have a very minor contribution and it is difficult to calculate. Hence, the structural contribution to enthalpy has been usually neglected (Basu, et al., 2008). In the case of the elastic and structural contributions are absent, thus the formation enthalpy of glasses can be calculated as

$$
\Delta H^{\text {amor }}=\Delta H^{\text {chem }}(\text { amor })+3.5 \sum_{1}^{n} x_{i} T_{m, i}
$$

Where $x_{i}$ represents the mole fraction of component $i$ atom, $T_{m, i}$ is the melting temperature of the component $i$.

According to the Miedema's model, an amorphous phase can be formed if the enthalpy of formation of the amorphous phase is less than that of the solid solution phase. The heat of formation in alloys generally arises from the interactions among the constituent atoms where the interfacial energy plays a major role. The interfacial energy mainly comes from the atomic size difference. It has also been postulated that the number of intermetallic phases appearing in an alloy system is a strong function of the heat of mixing. The number of intermetallic phase in an alloy system increases with the increase in the heat of mixing. This model can be directly used to determine the glass forming range in binary alloy systems and can be extended to ternary systems by neglecting the ternary interactions.

\subsubsection{Calculation of the GFA for the binary alloy systems}

Since the metallic glass formation process is controlled by thermodynamic factors, Miedema's model was firstly used to predict the composition range of amorphous binary transition metal alloys (Kolk et al., 1988; Coehoorn et al., 1988; Murty, et al., 1992; Basu, et al., 2008). It is found that the predicted glass forming composition ranges are in good agreement with the experimental results. In the work of Takeuchi and Inoue (Takeuchi \& Inoue, 2000), this approach has been used to calculate the mixing enthalpy and mismatch entropy of a number of bulk metallic glass alloy systems. It has been observed that the mixing enthalpy and normalised mismatch entropy for glass forming alloys vary within a certain range. 

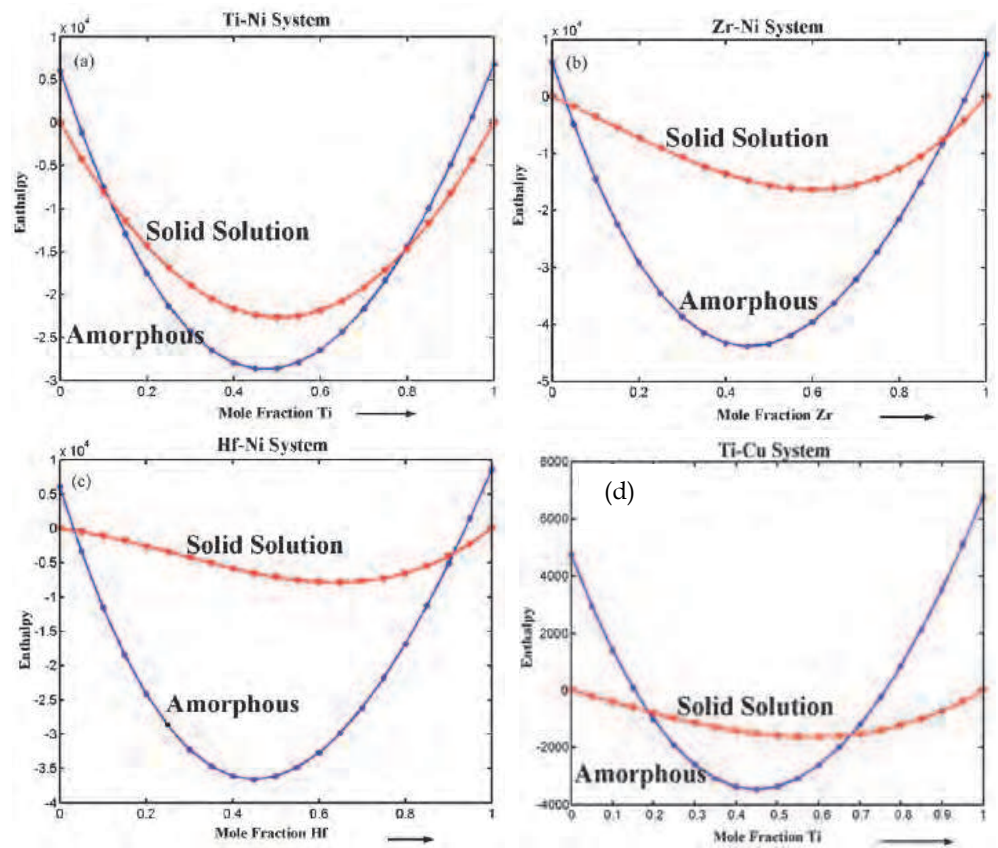

Fig. 2. Enthalpy-composition curves for binary Ti-Ni, Zr-Ni, Hf-Ni, Ti-Cu alloy systems (ad). The curve with $(\bullet)$ and the curve with $(\Delta)$ represent amorphous and solid solution phase, respectively. The enthalpy values are in $\mathrm{J} / \mathrm{mol}$ (From Basu, et al., 2008).

As shown in Fig. 2, in the work of Basu et al. (Basu, et al., 2008), glass forming range (GFR) has been determined for different binary (Ti-Ni, $\mathrm{Zr}-\mathrm{Ni}, \mathrm{Hf}-\mathrm{Ni}, \mathrm{Ti}-\mathrm{Cu}, \mathrm{Zr}-\mathrm{Cu}, \mathrm{Hf}-\mathrm{Cu}$ ) in $(\mathrm{Zr}, \mathrm{Ti}, \mathrm{Hf})-(\mathrm{Cu}, \mathrm{Ni})$ alloys based on the mixing enthalpy and mismatch entropy calculations. Though copper and nickel appear next to each other in the periodic table, the glass forming ability of the copper and nickel bearing alloys is different. Thermodynamic analysis reveals that the glass forming behaviour of $\mathrm{Zr}$ and $\mathrm{Hf}$ is similar, whereas it is different from that of $\mathrm{Ti}$. The smaller atomic size of $\mathrm{Ti}$ and the difference in the heat of mixing of $\mathrm{Ti}, \mathrm{Zr}$, Hf with $\mathrm{Cu}$ and $\mathrm{Ni}$ leads to the observed changes in the glass forming behaviour. Enthalpy contour plots can be used to distinguish the glass forming compositions on the basis of the increasing negative enthalpy of the composition. This method reveals the high glass forming ability of binary $\mathrm{Zr}-\mathrm{Cu}, \mathrm{Hf}-\mathrm{Cu}, \mathrm{Hf}-\mathrm{Ni}$ systems over a narrow composition.

In the recent work performed by Xia (Xia, et al., 2006), the GFA of an alloy is considered that the formation of the meta-stable amorphous state should include two aspects: (1) the driving force for the glass formation, i.e., $-\Delta H^{\mathrm{amor}}$, and (2) the resistance of glass formation against crystallization, i.e. the difference between the driving force for glass phase and for the

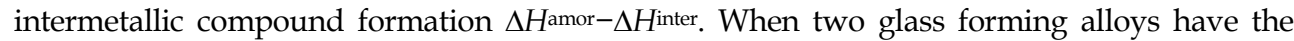
same $-\Delta H$ amor but different $\Delta H^{\text {amor }}-\Delta H^{\text {inter }}$, their GFA can then be dominated by $\Delta H^{\text {amor }}-\Delta H^{\text {inter }}$.

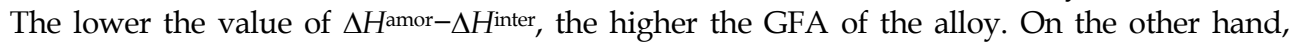

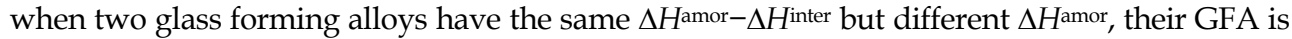

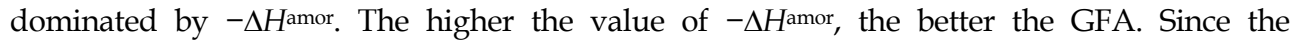


contribution from entropies is much smaller as compared with that from the formation enthalpy of solid compounds (Delamare, et al., 1994), the GFA is expressed in terms of formation enthalpy alone. Based on this thermodynamic consideration, a new parameter $\gamma^{*}$ to evaluate GFA for glass formation was proposed by Xia et al. (Xia, et al., 2006) and expressed as

$$
\gamma^{*}=G F A \propto \frac{\Delta H^{\text {amor }}}{\Delta H^{\text {inter }}-\Delta H^{\text {amor }}}
$$

where $\Delta H^{\text {amor }}$ and $\Delta H^{\text {inter }}$ are the enthalpies for glass and intermetallic formation, respectively. Both $\Delta \mathrm{H}^{\mathrm{amor}}$ and $\Delta \mathrm{H}^{\mathrm{inter}}$ are calculated by Miedema's macroscopic atom model. This parameter has been successfully used to predict the GFR and the best GFA alloy compositions in $\mathrm{Zr}-\mathrm{Cu}$ and $\mathrm{Ni}-\mathrm{Nb}$ system by comparing the value of $\gamma^{*}$ of various alloy systems, respectively (Xia, et al., 2006).
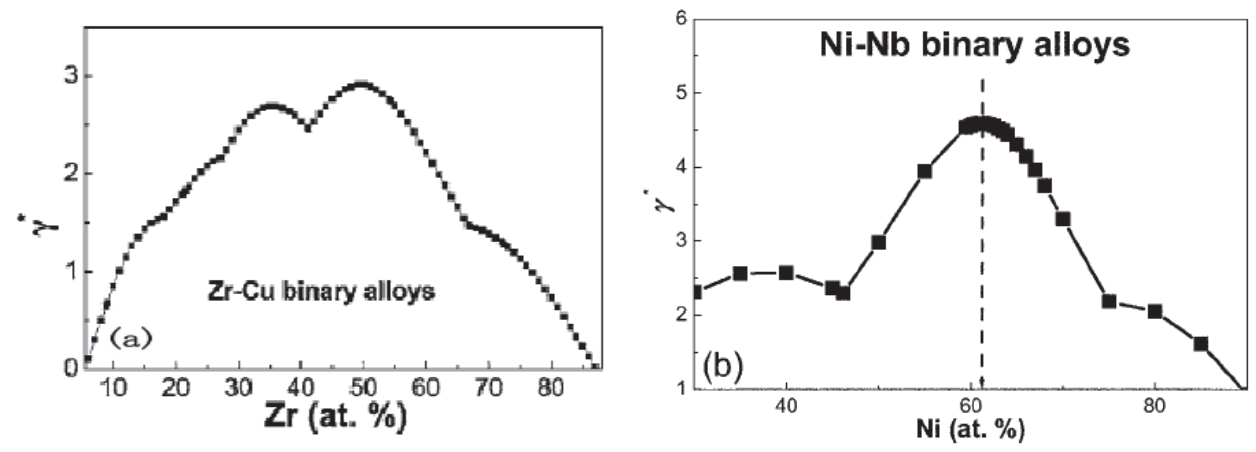

Fig. 3. Calculated dependence of the parameter $\gamma^{*}$ on $\mathrm{Zr}$ and Ni concentration in $\mathrm{Cu}-\mathrm{Zr}$ (a) and $\mathrm{Ni-Nb}$ (b) binary alloys, respectively (from Xia, et al., 2006).

Fig. 3 shows the calculated dependence of the parameter $\gamma^{*}$ on $\mathrm{Zr}$ and $\mathrm{Ni}$ concentration in $\mathrm{Cu}-\mathrm{Zr}(\mathrm{a})$ and $\mathrm{Ni}-\mathrm{Nb}(\mathrm{b})$ binary alloys, respectively, suggesting that the alloys $\mathrm{Cu}_{64} \mathrm{Zr}_{36}$ and $\mathrm{Cu}_{50} \mathrm{Zr}_{50}$ in $\mathrm{Cu}-\mathrm{Zr}$ system, and $\mathrm{Ni}_{61.5} \mathrm{Nb}_{38.5}$ in $\mathrm{Ni}-\mathrm{Nb}$ system are the best glass former, respectively. These predicted results are in good agreement with the experimentally reported $\mathrm{Cu}_{64.5} \mathrm{Zr}_{35.5}$ and $\mathrm{Cu}_{50} \mathrm{Zr}_{50}$, and $\mathrm{Ni}_{62} \mathrm{Ni}_{38}$ that could be made into bulk metallic glass rods with $2 \mathrm{~mm}$ in diameter, indicating that $\gamma^{*}$ is an effective parameter in identifying the best glass former in the $\mathrm{Zr}-\mathrm{Cu}$ and $\mathrm{Ni}-\mathrm{Nb}$ binary system.

Similarly, considering both the stability of liquid employing $\Delta \mathrm{H}^{\mathrm{liq}} / \Delta \mathrm{H}^{\mathrm{inter}}$, and the

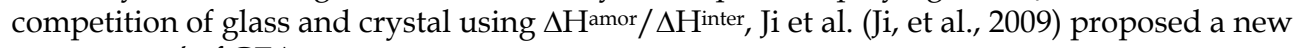
parameter $\gamma^{\prime}$ of GFA as

$$
\gamma^{\prime}=G F A \propto \frac{\Delta H^{l i q} \bullet \Delta H^{\text {amor }}}{\left(\Delta H^{\text {inter }}\right)^{2}}
$$

As Ji et al. described, this parameter $\gamma^{\prime}$ is not only verified in five different binary bulk metallic glasses ( $\mathrm{Cu}-\mathrm{Hf}, \mathrm{Ni}-\mathrm{Nb}, \mathrm{Cu}-\mathrm{Zr}, \mathrm{Ca}-\mathrm{Al}, \mathrm{Pd}-\mathrm{Si}$ ) but also showed wider application range comparing with the former model, but also have a better GFA estimation on the different composition than the parameter $\gamma^{*}$ because it is including $\Delta \mathrm{H}^{\text {liq }}$ in the evaluation expression. The predicated results are in good agreement with the experiments in all five different kinds of binary BMG systems and the biggest deviation of the peak of $\gamma^{\prime}$ from the 
best current GFA composition is only about 6 at.\% in Ca-Al alloy. Comparing with former GFA parameter $\gamma^{*}, \gamma^{\prime}$ takes account of liquid stability and shows more universal for evaluation GFA in different kinds of binary alloys (Ji, et al., 2009). Recently, Wang et al. also made a modification to Xia's proposal and it works more convenient to describe the GFA of transition metal systems (Wang, et al., 2009).

\subsubsection{Calculation of the GFA for the multicomponent alloy systems}

Miedema's approach has been extensively used by Nagarajan and Ranganathan (Nagarajan \& Ranganathan, 1994), Takeuchi and Inoue (Takeuchi \& Inoue, 2001 \&2004) and other researchers (Murty, et al., 1992; Rao, et al.; 2007; Basu, et al, 2008; Wang \& Liu, 2009; Sun, et al., 2010) to determine the glass forming composition range (GFR) in a number of ternary and multicomponent systems. In the work performed by Takeuchi and Inoue (Takeuchi \& Inoue, 2001), the amorphous-forming composition range (GFR) was calculated for 338 ternary amorphous alloy systems on the basis of the database given by Miedema's model in order to examine the applicability of the model, to analyze the stability of the amorphous phase, and to determine the dominant factors influencing the ability to form an amorphous phase. The mixing enthalpies of amorphous and solid solution phases were expressed as a function of alloy compositions on the basis of chemical enthalpy. The GFR was calculated for 335 systems except for the Al-Cu-Fe, Al-Mo-Si and Au-Ge-Si systems. The calculated results are in agreement with the experimental data for $\mathrm{Cu}-\mathrm{Ni}$ - and $\mathrm{Al}-\mathrm{Ti}$-based systems. For typical amorphous alloy systems exemplified by the $\mathrm{Zr}-$, La-, Fe- and Mg-based systems, it was recognized that the calculated GFR had been overestimated as a result of the model being simplified. It is found that the elastic enthalpy term arising in a solid solution phase stabilizes the amorphous phase, and the stabilization mechanism is particularly notable in Mg-based amorphous alloy systems. Short-range order plays an important role in the formation of Al-, Fe- and Pd-metalloid based systems (Takeuchi \& Inoue, 2001).

Based on Miedema's model and Alonso's method, the glass forming ability/range (GFA/ GFR) of the Fe-Zr-Cu system was studied by thermodynamic calculation. It is found that when the atomic concentration of $\mathrm{Zr}$ is between $34 \%$ and $56 \%$, no matter what the atomic concentrations of $\mathrm{Fe}$ and $\mathrm{Cu}$ are, amorphous phase could be obtained, thus the atomic mismatch playing a dominating role in influencing the GFA. While the atomic concentration of $\mathrm{Zr}$ is out of the above range, the GFA is highly influenced by the immiscibility between Fe and $\mathrm{Cu}$ (Wang \& Liu, 2009).

Glass forming composition range for ternary $\mathrm{Zr}-\mathrm{Ti}-\mathrm{Ni}$, Zr-Hf-Ni, Ti-Hf-Ni, Zr-Ti-Cu, Zr$\mathrm{Hf}-\mathrm{Cu}$ and Ti-Hf-Cu systems has been determined by extending the Miedema's model to ternary alloy systems and by neglecting the ternary interaction parameter (Basu, et al., 2008). In their calculations, solid pure metals have been chosen to be the standard state and their enthalpy has been assigned to be zero. It is seen that the glass forming composition range for $\mathrm{Ni}$ bearing alloys is higher than that of the $\mathrm{Cu}$ bearing alloys, as heat of mixing of $\mathrm{Ni}$ is higher than that of $\mathrm{Cu}$ with $\mathrm{Ti}, \mathrm{Zr}$ and $\mathrm{Hf}$. In these ternary $(\mathrm{Zr}, \mathrm{Ti}, \mathrm{Hf})-(\mathrm{Cu}, \mathrm{Ni})$ alloys mixing enthalpy and mismatch entropy varies between $(-13)$ and $(-42) \mathrm{kJ} / \mathrm{mol}$ and 0.13 and 0.25 , which is within the range predicted for glass formation (Basu, et al., 2008).

In the work of Oliveira et al., the $\gamma^{*}$ parameter proposed by Xia et al. was extended to the ternary Al-Ni-Y system. The calculated $\gamma^{*}$ isocontours in the ternary diagram are compared with experimental results of glass formation in that system. Despite some misfitting, the best glass formers are found quite close to the highest $\gamma^{*}$ values, leading to the conclusion that 
this thermodynamic approach can be extended to ternary systems, serving as a useful tool for the development of new glass-forming compositions (Oliveira et al., 2008).

Rao et al. (Rao et al. 2007) identified the composition with highest glass forming ability in $\mathrm{Zr}-\mathrm{Ti}-\mathrm{Ni}-\mathrm{Cu}-\mathrm{Al}$ quinary systems with the Gibbs-energy change between the amorphous and solid solution phases as the thermodynamic parameter by calculating the Gibbs-energy change with the help of Miedema, Miracle, mismatch entropy and configurational entropy models. $\Delta \mathrm{G}$ shows the strong correlation with the reduced glass transition temperature $\left(\mathrm{T}_{\mathrm{g}} / \mathrm{T}_{\mathrm{l}}\right)$ in $\mathrm{Zr}$-based metallic glasses. Thus, $\Delta \mathrm{G}$ can be used as a predictive GFA parameter to identify compositions with the highest GFA. The compositions with the highest GFA have been identified in a number of quinary systems by iso-free energy contour maps by representing quandary systems as quasiternary systems (Rao et al. 2007). The best glass forming composition has been identified by drawing iso-Gibbs-energy change contours by representing quinary systems as pseudo-ternary ones. Attempts have been made to correlate the Gibbs-energy change with different existing glass forming criteria and it is found that the present thermodynamic parameter has good correlation with the reduced glass transition temperature. Further, encouraging correlations have been obtained between the energy required for amorphization during mechanical alloying to the Gibbs-energy change between the amorphous and solid solutions.

\subsection{Calculation of the GFA of alloys based on driving force criterion}

\subsubsection{Method}

The basic underlying concept to predict the compositions of alloys having high GFA using the thermodynamic approach is that the compositions exhibiting the local melting minimum points favour amorphous phase formation. Thermodynamic approach of driving force criterion is based on a different concept. During a melt-quenching process for metallic glass formation, the glass formation is exposed to crystallization competition of other crystalline phases from the undercooled melt between liquidus temperature $T_{1}$ and glass transition $T_{\mathrm{g}}$. It is well known that the crystallization is the only event that prevents the formation of amorphous phase. Considering that crystallization is usually through the nucleation and growth process, the high GFA can be inversely predicted by searching a condition where the nucleation and growth of crystalline phases can be retarded. There are three dominating factors for the kinetics, (i) chemical driving force, (ii) interfacial energy, as an energy barrier, between the amorphous phase and the crystalline phases, (iii) the atomic mobility for rearrangement or transport of the partitioning atoms. According to the classical nucleation theory, the driving force of formation of the crystalline phases and interfacial energy, among other things, affects the nucleation rate of product phases. The interfacial energy between liquid and crystalline phases is known to be small compared to surface energy or grain boundary energy (Porter \& Easterling, 1992), and therefore the role of interfacial energy in the nucleation kinetics of crystalline phases would be small. Then, the driving force of formation becomes the major factor that affect the nucleation kinetics of crystalline phases from amorphous alloy melts. It is believed that alloys with lower driving force for the formation of crystalline phases under the supercooled liquid state suggest higher GFA in the glass forming range. Therefore, Kim and co-workers proposed the minimum driving force criterion as a new thermodynamic calculation scheme to evaluate the composition dependence of the GFA (Kim et al., 2004). The driving force for the crystalline phases can be calculated using the critical assessed thermodynamic parameters by the CALPHAD method (Kaufman \& Bernstein, 1970). In the CALPAHD method, the Gibbs energies of individual phases are described using 
thermodynamic models. Then, the model parameters are optimized considering relevant experimental information on phase equilibria or the other thermodynamic properties. The calculation of phase equilibrium is performed based on the minimum Gibbs energy criterion.

\subsubsection{Application of the driving force criterion}

Driving force criterion has been successfully used to explain the composition dependence of GFA in several glass forming alloys with unique GFA, such as $\mathrm{Cu}-\mathrm{Zr}-\mathrm{Ti}$ (Kim, et al., 2004), Mg-Cu-Y (Kim, et al., 2005), Al-Ce-Ni (Tang, et al. 2010), and Al-Cu-Zr (Bo, et al, 2010) systems, by calculating the driving force of formation of crystalline phases under metastable supercooled liquid states and by searching the local minima of the driving forces for crystallization. The calculated results are in good agreement with the experimental results. It has been indicated that the driving force criterion can be used as a new thermodynamic scheme to estimate the composition dependence of GFA in multicompoent alloy systems for the development of bulk amorphous alloys.
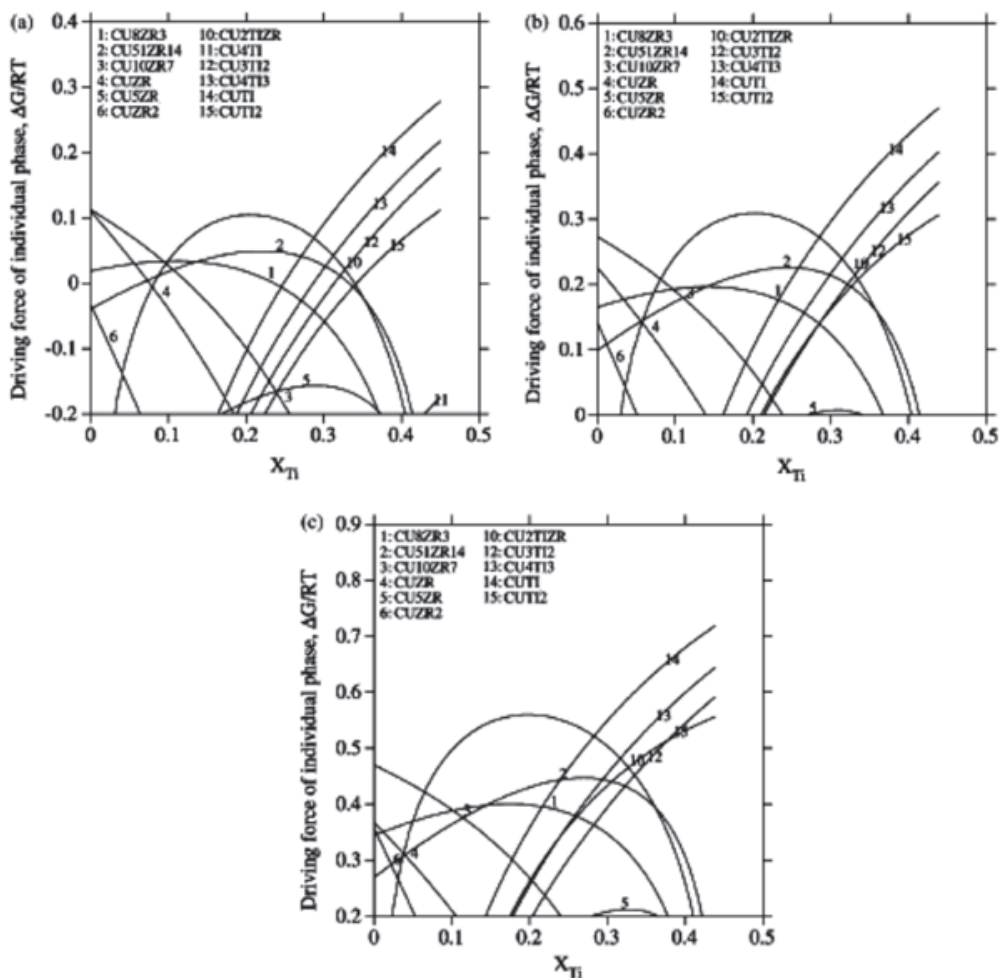

Fig. 4. Calculated driving forces of crystalline phases for $\mathrm{Cu}_{55} \mathrm{Zr}_{45-\mathrm{x}} \mathrm{Ti}_{\mathrm{x}}$ alloys, versus $\mathrm{Ti}$ content at (a) $1073 \mathrm{~K}$, (b) $973 \mathrm{~K}$, and (c) $873 \mathrm{~K}$ (from Kim, et al., 2004).

For the Cu-Zr-Ti system, among a series of ternary alloys $\mathrm{Cu}_{60} \mathrm{Zr}_{40-\mathrm{x}} \mathrm{Ti}_{\mathrm{x}}(\mathrm{x}=10,20,30)$, the alloy with the highest GFA should be the alloy $\mathrm{Cu}_{60} \mathrm{Zr}_{20} \mathrm{Ti}_{20}$ according to the maximum $\mathrm{T}_{\mathrm{rg}}$ criterion (Turnbull, 1969), while experiments (Inoue, et al., 2001) show it is $\mathrm{Cu}_{60} \mathrm{Zr}_{30} \mathrm{Ti}_{10}$. Although the other alloys, $\mathrm{Cu}_{55} \mathrm{Ti}_{35} \mathrm{Zr}_{10}$ (Lin \& Johnson, 1995) and $\mathrm{Cu}_{47} \mathrm{Ti}_{33} \mathrm{Zr}_{11} \mathrm{Ni}_{8} \mathrm{Si}_{1}$ (Choi, et 
al., 1998) based on the $\mathrm{Cu}-\mathrm{Ti}-\mathrm{Zr}$ ternary system but at different region, have been published as alloys with high GFA, there is no empirical rule or factor that can explain why the high GFA is obtained at certain compositions in the $\mathrm{Cu}-\mathrm{Ti}-\mathrm{Zr}$ system (roughly $\mathrm{Zr}$ : $\mathrm{Ti}=3: 1$ and $\mathrm{Zr}$ : $\mathrm{Ti}=1: 3$ ). As already the thermodynamic parameters for all phases in this system obtained by the CALPHAD method, the GFA is estimated by calculating the driving forces of all crystalline phases under the undercooled liquid state. Fig. 4 shows the calculated driving forces of individual crystalline phases as a function of $\mathrm{Ti}$ content in a temperature range $\left(600-800{ }^{\circ} \mathrm{C}\right)$ where the alloys correspond to supercooled liquids state. As shown in this figure, along the composition line $\mathrm{Cu}_{55} \mathrm{Zr}_{45-\mathrm{x}} \mathrm{Ti}_{\mathrm{x}}$ with varying Ti content, the driving forces of crystalline phases show two local minimums, one at Zr-rich region $(x=7-10)$ and the other at Ti-rich region $(x=28-29)$. According to the driving force criterion, the two local minimum points in Fig. 4 are the compositions where the GFA is expected to be higher than other compositional region. In a sense that the Zr:Ti ratios in the two local minimum points are toughly close to 3:1 and 1:3, it can be said that the former is close to the Inoue's composition and the latter is close to Johnson's composition (Kim et al., 2004). This finding indicates that the composition dependency of the GFA in the $\mathrm{Cu}-\mathrm{Zr}$-Ti ternary alloy system can be explained by calculating the driving forces of formation of crystalline phases under metastable supercooled liquid states and by searching the local minima of the driving forces for crystallization (Kim, et al. 2004).

Similarly, Al-based amorphous, which was discovered in 1988 (He, et al., 1988 \& Inoue, et al., 1988), is also of particular interest because of its low density, good bending ductility and high tensile strength. It was found that, however, most of above mentioned parameters and rules capable of searching metallic glasses with high GFA are not applicable to Al-based amorphous (Guo, et al., 2000, Hackenberg, et al., 2002, Gao, et al., 2003, Zhu, et al. 2004).AlCe-Ni system is an unique Al-based system, which can be synthesized into a strong, flexible metallic glass with the widest GFR covering 2-15 at.\% Ce and 1-30 at.\% Ni (Inoue, 1998, Kawazoe et al., 1997). The alloys with high GFA are situated away from the eutectic point. Experimental results of the Al-Ce-Ni bulk amorphous alloys prepared with copper mold casting indicate that the amorphous sheets with $5 \mathrm{~mm}$ width and $0.2 \mathrm{~mm}$ thickness are obtained in $\mathrm{Al}_{86} \mathrm{Ce}_{4} \mathrm{Ni}_{10}$ and $\mathrm{Al}_{88} \mathrm{Ce}_{6} \mathrm{Ni}_{6}$ alloys without appreciable glass transition. On contrary, alloys $\mathrm{Al}_{82} \mathrm{Ce}_{8} \mathrm{Ni}_{10}$ and $\mathrm{Al}_{80} \mathrm{Ce}_{6} \mathrm{Ni}_{14}$ with $\triangle \mathrm{Tx}$ values of 20 and $21 \mathrm{~K}$ consist mainly of crystalline phases (Inoue, 1998). After a thermodynamic assessment of the Al-Ce-Ni system in the Al-rich corner was performed, a set of consistent thermodynamic parameters were obtained, and the thermodynamic properties of the Al-Ce-Ni amorphous alloys were calculated. The calculated results indicated that the alloys with high GFA in the Al-Ce-Ni system are far from the eutectic point, and the heats of mixing are from -15 to $-49 \mathrm{~kJ} / \mathrm{mol}$ of atom for the observed amorphous alloys (Tang et al., 2010).

As shown in Fig. 5, the relatively smaller nucleation driving forces for the formation of crystalline phases for the Al-10Ce based alloys (Fig. 5a) are generally indicative of their higher GFA with a reportedly wider GFR (1-30at.\% Ni) (Kawazoe et al., 1997). In contrast, the relatively larger driving forces in the Al-10Ni based alloys (Fig. $7 \mathrm{~b}$ ) are associated with their poorer GFA and narrower GFR (2-10 at.\% Ce) (Kawazoe et al., 1997). This finding is further confirmed by the melt spinning (Tang, et al., 2010) and the copper mold casting experimental results (Inoue, 1998).

Based on the experimental enthalpies of mixing of ternary liquid and undercooled liquid alloys as well as the evaluated isothermal sections, the Al-Cu-Zr ternary system has been assessed using the CALPHAD method. Most of the calculated results show good agreement 
with the experimental thermodynamic data and the reported phase diagrams. By employing the driving force criterion with the present thermodynamic description, the observed glassforming ability in the Al-Cu-Zr system can be accounted for satisfactorily (Bo, et al., 2010).
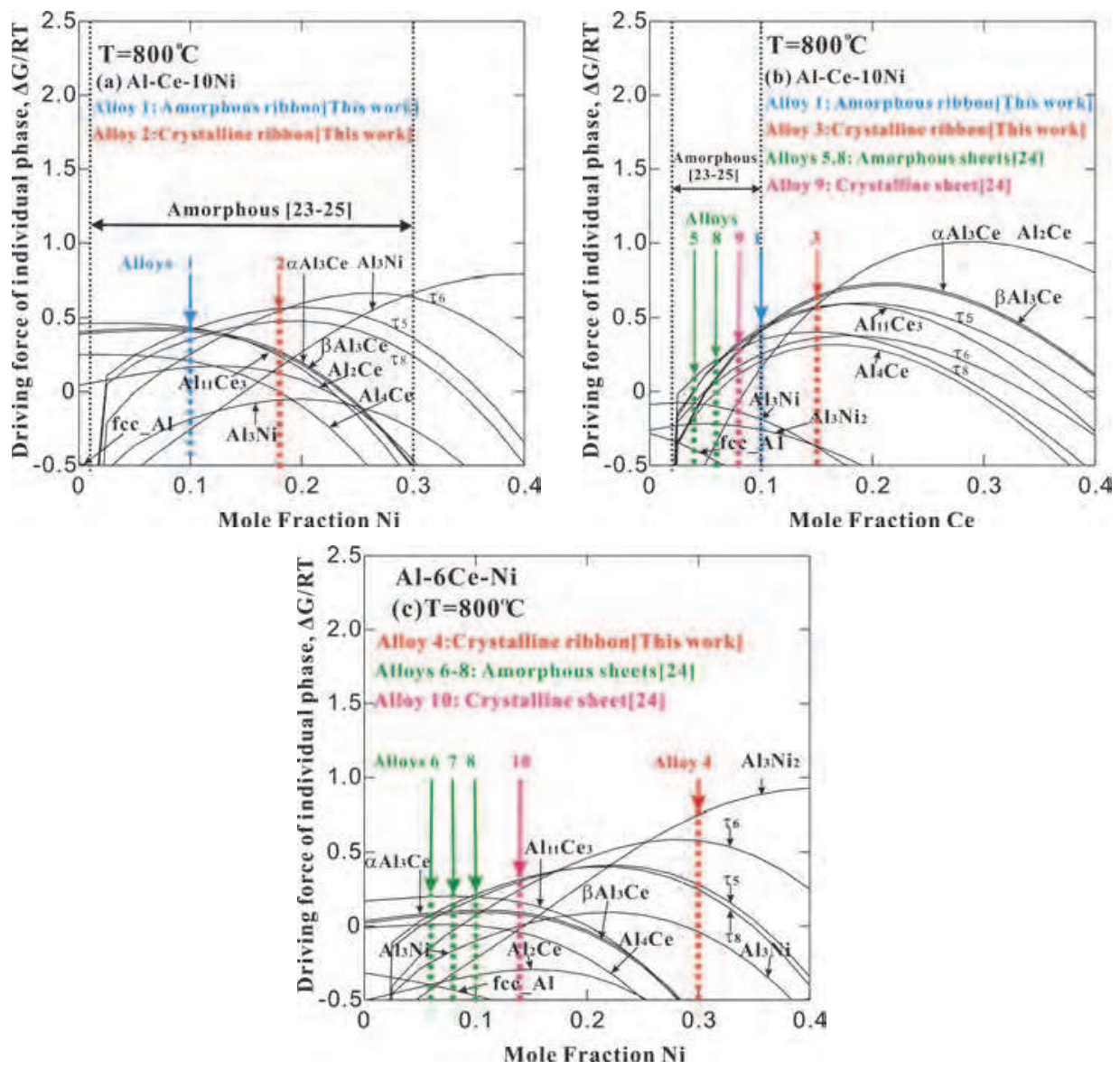

Fig. 5. Calculated normalized nucleation driving force (per mole of atoms) for crystalline phases from undercooled (a) Al-10Ce-Ni, (b) Al-Ce-10Ni and (c) Al-6Ce-Ni metastable liquid at $800{ }^{\circ} \mathrm{C}$ (from Tang, et al., 2010).

\subsection{Calculation of the GFA of alloys based on the other thermodynamic approach}

By treating the glass transition as a second-order phase transformation from liquid phase (Palumbo, et al., 2001, Shao et al., 2005), which can give good predictions of all important GFA indicators such as the reduced glass transition temperature and the thermodynamic stability of the amorphous phase, Shao et al. established a full thermodynamic database for glass forming ability (GFA). The resultant thermodynamic database can be used to produce all major temperature-related GFA indicators such as $T_{g} / T_{l}, T_{g} / T_{m}$ and $T_{x} /\left(T_{g}+T_{l}\right)$. It is indicated that together with phase diagram prediction, such an extensive CALPHAD approach is a powerful tool for designing alloys with large GFA (Shao et al., 2005). 
By using the computational thermodynamic approach exhibiting low-lying liquidus surfaces coupled with the reduced glass transition temperature criterion of Turnbull, regions of alloy composition suitable for experimental tests for glass formation of $\mathrm{Zr}-\mathrm{Ti}-\mathrm{Ni}$ $\mathrm{Cu}-\mathrm{Al}$ system were identify rapidly by Cao et al. (Cao, et al., 2006). The glass forming ability of the alloys we studied can be understood in terms of the relative liquidus temperature in a thermodynamically calculated temperature vs. composition section through a multicomponent phase diagram. It does not follow several other proposed thermodynamic or topological criteria.

A thermodynamic parameter $\left(\Delta \mathrm{H}^{\text {chem }} \times \mathrm{S}_{\sigma} / \mathrm{k}_{\mathrm{B}}\right)$ in the configuration entropy $\left(\mathrm{S}_{\text {config }} / \mathrm{R}\right)$ range of 0.8-1.0 has been developed to identify excellent BMG composition using enthalpy of chemical mixing $\left(\Delta H^{\text {chem }}\right)$, the mismatch entropy normalized by Boltzmann's constant $\left(\mathrm{S}_{\sigma} / \mathrm{k}_{\mathrm{B}}\right)$ and the configurational entropy $\left(\mathrm{S}_{\text {config }} / \mathrm{R}\right)$ by Bhatt et al. and it has been demonstrated for the $\mathrm{Zr}-\mathrm{Cu}-$ $\mathrm{Al}$ based ternary system. It is found that this approach can be used to predict the best BMG composition more closely than the earlier models (Bhatt, et al., 2007).

Based on the undercooling theory resulting from the existence of multicomponent chemical short-range order (CSRO) domains, the glass forming range (GFR) in $\mathrm{Zr}-\mathrm{Ni}$-Ti alloy system was predicted by thermodynamic calculation. The GFR predicted by the thermodynamic calculation is consistent with the experiment results (Liu, et al. 2008).

One of the ways to predict the possible bulk glass formation composition is the phase diagram calculation with suppression of the formation of intermetallic phases. The formation of stoichiometric intermetallic compounds which have the ordered structure of atoms into specific lattice sites can take a time for the rearrangement of atoms from liquid state. Thus, the formation of intermetallic compounds can be suppressed during the fast solidification process normally applied to the bulk glass production. Combining the obtained the thermodynamic database and the above concept, the amorphous formation diagram of the $\mathrm{Cu}-\mathrm{Zr}-\mathrm{Ag}$ system with the suppression of all binary and ternary intermetallic phases has been proposed by Kang and Jung (Kang \& Jung, 2010)

\section{Calculation of the GFA of alloys based on a combined thermodynamics and kinetics approach}

As discussed above, the thermodynamic approach is useful since the thermodynamic parameters can be used to calculate the GFR in binary alloys and can also be used to predict the GFR in ternary systems based on the constituent binaries. One of the limitations of a purely thermodynamic approach is that it does not give the critical cooling rates for the glass formation. A combined thermodynamic and kinetic treatment, based on timetemperature-transformation curves (TTT) in the manner of Uhlmann and Davies has been presented (Saunders \& Miodownik, 1986 \& 1988). This combined approach takes the thermodynamic parameters obtained from the phase diagram calculations and derives values for the free energy barrier for nucleation, free energy driving forces, and melting points used in kinetic equations. The combined approach has been successfully used to calculate the glass forming ability (GFA) of a wide range of binary and ternary alloy systems (Saunders \& Miodownik, 1988). The calculated glass forming ranges for a wide number of binary and ternary alloy systems are in good agreement with experiment. A significant advantage of the combined approach is that data from binary alloy systems, often with little or no ternary modification, can be used to calculate the necessary thermodynamic input for the kinetic equations in higher order systems. This section outlines briefly the combined thermodynamic and kinetics method used for the calculation of the GFA for alloy systems. 


\subsection{Method}

Critical cooling rates for glass formation can be obtained by Johnson-Mehl-Avrami isothermal transformation kinetics using the equation

$$
X=1-\exp \left[(-\pi / 3) I_{v} U_{c}^{3} t^{4}\right]
$$

where $\mathrm{X}$ is the volume fraction of material transformed, $\mathrm{I}_{\mathrm{v}}$ is the nucleation frequency, $\mathrm{U}_{\mathrm{c}}$ is the crystal growth rate, and $t$ is the time taken to transform $X$. In the early stages of transformation the value of $X$ approximates to

$$
X \cong \pi I_{v} U_{c}^{3} t^{4}
$$

For homogeneous nucleation without pre-existing nuclei, the nucleation frequency $I_{v}^{h}$ is given by

$$
I_{v}^{h}=\frac{D_{n} N_{v}}{a_{0}^{2}} \exp \left(-\Delta G^{*} / k T\right)
$$

where $D_{\mathrm{n}}$ is the diffusion coefficient necessary for crystallisation, $N_{\mathrm{v}}$ is the number of atoms per unit volume. $a_{0}$ is an atomic diameter. $k$ is Boltzmann's constant. $\mathrm{T}$ is the transformation temperature, and $\Delta G^{*}$ is the free energy barrier for nucleation of a spherical nucleus given by the expression

$$
\Delta G^{*}=\frac{16 \pi}{3}\left(\sigma^{3} / G_{v}^{2}\right)
$$

where $\sigma$ is the liquid/crystal interfacial energy and $G_{v}$ is the change in free energy per unit volume on solidification. An equation for $U_{c}$ can be written as

$$
U_{c}=\frac{f D_{g}}{a_{0}}\left[1-\exp \left(-\Delta G_{m} / R T\right)\right]
$$

where $D_{\mathrm{g}}$ is the diffusion coefficient for the atomic motion necessary for liquid to crystal growth, $\Delta G_{m}$ is the molar free energy driving force for liquid to crystal growth, and $R$ is the universal gas constant, and $f$ is a structural constant denoted the fraction of sites on the interface where atoms may preferentially be added or removed, and is given by the following expression (Uhlmann, 1972)

$$
f=0.2\left(T_{m}-T\right) / T_{m}
$$

where $T_{\mathrm{m}}$ is the liquidus temperature. By assuming that $D_{\mathrm{n}}=D_{\mathrm{g}}=$ the bulk liquid diffusivity and invoking the Stokes-Einstein relationship between diffusivity and viscosity $\eta$, equation (12) and (14) can be derived to give the time $t$ needed to form a volume fraction $X$ of transformed crystalline phase in an undercooled liquid as following

$$
t \approx \frac{9.3 \eta}{k T}\left\{\frac{a_{0}^{9} X}{f^{3} N_{v}} \frac{\exp \left(\Delta G^{*} / k T\right)}{\left[1-\exp \left(-\Delta G_{m} / R T\right)\right]^{3}}\right\}^{1 / 4}
$$


where $t$ is the time taken to transformation volume fraction $X$ of crystalline solid. $\eta$ is the viscosity of liquid, $a_{0}$ is an atomic diameter, $f$ is a structural constant, $N_{v}$ is the number of atoms per unit volume, $\Delta G^{*}$ is the Gibbs energy barrier to nucleation and $\Delta G_{m}$ is the Gibbs energy driving force for the liquid-crystal transformation. The constants have been typically taken as $X=10^{-6}, a_{0}=0.28 \times 10^{-9} \mathrm{~m}, f=0.1$ and $N_{v}=5 \times 10^{28}$ atoms $/ \mathrm{m}^{3}$. In order to apply this equation to a real alloy system, it is necessary to derive or estimate the parameters $\eta, \Delta G^{*}$, and $\Delta G_{m}$ (Saunders \& Miodownik, 1988).

\subsection{Estimation of $\eta, \Delta G^{*}$, and $\Delta G_{m}$}

Since it is very difficult to measure experimentally the viscosity of supercooled liquid, there have been few measurements of it. In this case, the viscosity can be generally described as being between the liquidus temperature $T_{m}$ and the glass transition $T_{g}$ using a Doolittle-type expression involving the relative free volume $f_{\mathrm{T}}$ (Ramachandrarao, et al., 1977) as

$$
\eta=A \exp \left(B / f_{T}\right)
$$

where

$$
f_{T}=C \exp \left(-E_{H} / R T\right)
$$

$E_{\mathrm{H}}$ is the hole formation energy and $\mathrm{A}, \mathrm{B}$, and $\mathrm{C}$ are constants. Because of the lack of experimental data and the $E_{H}$ value was estimated by means of a direct relationship from $T_{g}$ (Ramachandrarao, et al., 1977). Assuming B is unity and $f_{\mathrm{T}}$ and $\eta$ are 0.03 and $10^{12} \mathrm{Ns} / \mathrm{m}^{2}$, respectively at $\mathrm{Tg}$, $\mathrm{A}$ and $\mathrm{C}$ have been approximated at $3.33 \times 10^{-3}$ and 10.1 , respectively. If $\mathrm{T}_{\mathrm{g}}$ values are not available, crystallisation temperatures $\mathrm{T}_{\mathrm{x}}$ are used as a first approximation.

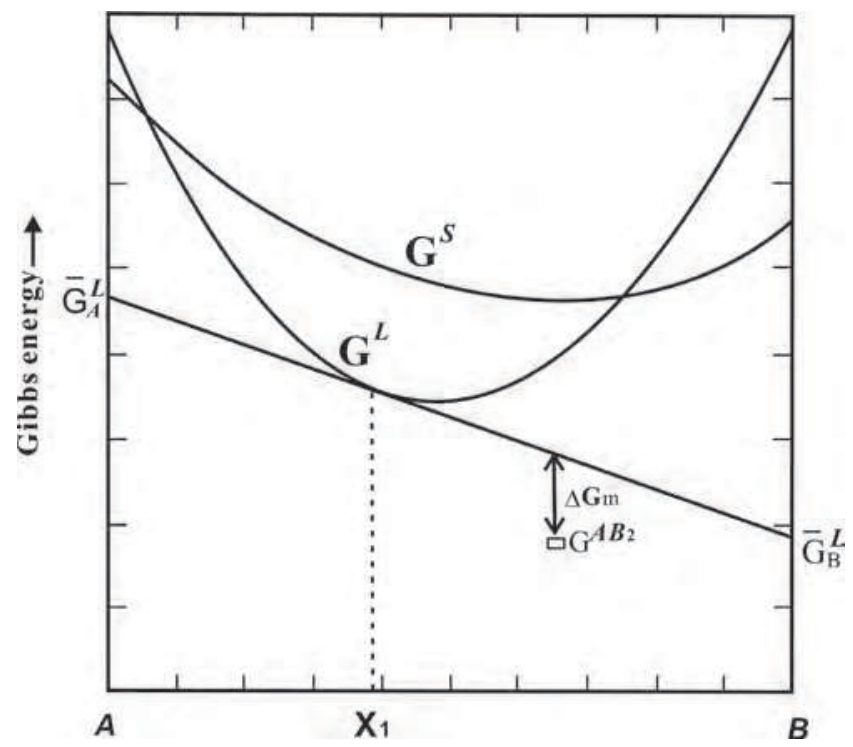

Fig. 6 . The construction used in calculating the driving force, $\Delta G_{m}$, for the crystallization of compound $\mathrm{AB}_{2}$ from a liquid of composition $x_{1}$ in the A-B system. 
For the crystallization of compounds $\mathrm{AB}_{2}$ from a liquid of composition $\mathrm{x}_{1}$ in the A-B system (Fig. 6), the molar free energy driving force for liquid to crystal growth, $\Delta G_{m}$, represents the Gibbs energy required to form one mole of crystalline phase from the liquid of composition $\mathrm{x}_{1}$, which can be obtained from thermodynamic phase diagram calculations to give explicitly molar heats of fusion $H_{m}^{f}$ and driving force that can be used to $\Delta G^{*}$. Values of $H_{m}^{f}$ and $\Delta G_{m}$ are calculated from partial molar Gibbs energies of elements $A$ and B and free energy values. Therefore, $\Delta G_{m}$ is expressed by the following equation

$$
\Delta G_{m}=x_{A} \bar{G}_{A}^{L}+x_{B} \bar{G}_{B}^{L}-G_{c r y s t}
$$

where $\mathrm{x}_{\mathrm{A}}$ and $\mathrm{x}_{\mathrm{B}}$ are the mole fractions of elements $\mathrm{A}$ and $\mathrm{B}$ in the precipitating crystalline phase, respectively. $\bar{G}_{A}^{L}$ and $\bar{G}_{B}^{L}$ are the partial molar Gibbs energies of elements A and B in the liquid phase, respectively, and $G_{\text {cryst }}$ is the integral free energy of the precipitating crystalline phase. The Gibbs energy functions in Eq. (19) can be obtained from the thermodynamic model parameters evaluated in the literature. In an A-B alloy system, a liquid composition $x_{1}$ becomes unstable with respect to the compounds $A_{2}$ at the liquidus temperature $T_{\mathrm{m}}$. At a given temperature $T_{1}$, there is a driving force for the precipitation of the compound $A B_{2}$ given by $G_{1}$ (Fig. 6), where $G_{1}$ is defined as the driving force to form one mole of compound $A_{2}$ in a liquid of composition $x_{1}$. In all cases here $\Delta G_{m}$ is equal to $\Delta G_{1}$. By using heats of formation in place of free energy values, $H_{m}^{f}$ can be similarly evaluated.

The Gibbs energy barrier to nucleation of a spherical nucleus $\Delta G^{*}$ can be described as

$$
\Delta G^{*}=\frac{16 \pi}{3 N}\left(\sigma_{m}^{3} / \Delta G_{m}^{2}\right)
$$

where $N$ is Avogadro's number and the $\sigma_{\mathrm{m}}$ the molar liquid/crystal interfacial energy. $\sigma_{\mathrm{m}}$ is directly related to the molar enthalpy of fusion $H_{m}^{f}$ and expressed as

$$
\sigma_{m}=\alpha H_{m}^{f}
$$

where $\alpha$ is a proportional constant. $H_{m}^{f}$ can be obtained in a similar way to evaluate $\Delta G_{m}$ based on bond energy values across the interface (Turnbull, 1950). Saunders and Miodownik empirically evaluated the constant $\alpha$ to be 0.41 (Saunders \& Miodownik, 1988).

\subsection{Calculation of critical cooling rates below $\mathrm{T}_{0}$ of disordered solid phases}

The expression for $t$ in equation (16) is derived assuming that the kinetics of the liquid to crystal transformation are limited by the bulk diffusivity, which is appropriate when the crystal composition differs from that of the liquid, or at compound compositions where substantial diffusion is necessary before the correct spatial relationships that define the ordered structure of the compound are achieved. However, at the temperatures below the $\mathrm{T}_{0}$ temperature of a disordered solid solution phase, the liquid becomes unstable with respect to a molecularly simple phase of the same composition. Consequently, no long range diffusion is necessary for the liquid to crystal and the kinetics are governed by atom motions of less than one atom in diameter. Then, the transformation is considered to be extremely difficult to suppress and this forms the $T_{0}$ criteria for GFA. In such cases, it has been suggested that the rate limiting step for crystal growth is proportional to the rate at which 
atoms collide at the liquid/crystal interface, and an expression for the crystal growth rate is then given (Boettinger et al., 1984) by

$$
U_{c}=f V_{0}\left[1-\exp \left(-\Delta G_{m} / R T\right)\right]
$$

where $V_{0}$ is the velocity of sound in the liquid metal. This is the same form as equation (14), but with $\mathrm{V}_{0}$ replacing the $\mathrm{D}_{\mathrm{g}} / \mathrm{a}_{0}$. Replacing the $\mathrm{D}_{\mathrm{n}} / \mathrm{a}_{0}$ in equation (12) with $\mathrm{V}_{0}$ and rearranging equation (12) and (14), an expression for $t$ is derived as

$$
t \approx \frac{1}{V_{0}}\left\{\frac{X a_{0}}{\pi f^{3} N_{v}} \frac{\exp \left(\Delta G^{*} / k T\right)}{\left[1-\exp \left(-\Delta G_{m} / R T\right)\right]^{3}}\right\}^{1 / 4}
$$

The value for $\mathrm{V}_{0}$ has been taken as $1000 \mathrm{~m} / \mathrm{s}$ by Saunders and Miodownik (Saunders \& Miodownik, 1988), close to the a value used by Boettinger et al. (Boettinger et al., 1984) and no transformation is considered to occur below $\mathrm{T}_{\mathrm{g}}$.

From equations (10) to (23), the time-temperature-transformation (TTT) curve can be obtained. The critical cooling rate $R_{c}$ necessary for amorphous phase formation with a melt quenching method can be evaluated from TTT curve calculated and approximated as follows

$$
R_{c}=\frac{T_{m}-T_{n}}{5 t_{n}}
$$

where $T_{m}$ and $t_{\mathrm{n}}$ are the temperature and time at the nose of the TTT curve, respectively, since the cooling rate calculated directly from the isothermal transformation curve is somewhat overestimated compared with that from the CCT (continuous cooling transformation) curve, the right side of Equation (24) has divided by a factor of 5 to emulate continuous cooling. In the composition range with $\mathrm{R}_{\mathrm{c}}<1 \times 10^{-7} \mathrm{~K} / \mathrm{s}$, which has been generally known to be a maximum available cooling rate for melting quenching, the amorphous phase formation may be possible.

\subsection{Evaluation of glass forming ranges in alloy systems}

The combined thermodynamic and kinetic approach has been undertaken to evaluate the GFA of a wide number of binary and ternary alloy systems since the pioneering work performed by Sanders and Miodownik (Saunders \& Miodownik, 1988; Shim et al., 1999; Clavaguera-Mora, 1995; Tokunaga, et al., 2004; Abe, et al., 2006; Ge, et al., 2008; Palumbo, \& Battezzati, 2008; Mishra \& Dubey, 2009). They calculated the free energy driving forces from the thermodynamic databases, free energy barrier for nucleation and melting points, and employed this data to kinetic calculation. There is in good agreement between the predicted glass forming ranges and those experimentally observed. It is indicated that the approach has the potential to predict glass forming ability in multicomponent alloys using mainly binary input data.

The first attempts to couple kinetic models with reliable thermodynamic data using the CALPHAD methodology was performed by Saunders and Miodownik (Saunders \& Miodownik, 1988). In his work, the combined thermodynamics and kinetics approach was presented in detail and undertaken to evaluate the GFA of a wide range of binary (Au-Si, Pd$\mathrm{Si}$, Ti-Be, Zr-Be, Hf-Be, Cu-Ti, Co-Zr, Ni-Zr, Cu-Zr, Ni-P, Pd-P) and ternary (Ni-Pd-P, Cu-Pd-P, 
Co-Ti-Zr, Zr-Be-Hf, Ti-Be-Hf) alloy systems (Saunders \& Miodownik, 1988). The TTT curves and the critical cooling rate for glass formation $R_{c}$ were estimated. There is excellent agreement between the predicted and observed GFRs of binary systems, apart from the discrepancies in the Ti-Be and $\mathrm{Cu}$-Ti systems. The approach was then extended to give predications for critical cooling rates in ternary and multicomponent alloys using mainly binary information. The results would appear to indicate that the combined approach takes into account a number of the major effects that govern glass formation and has the potential to predict GFA in multicomponent systems (Saunders \& Miodownik, 1988).

In the work performed by Ge et al., (Ge, et al., 2008), the glass forming ability (GFA) of nine compositions of $\mathrm{Cu}-\mathrm{Zr}$ and thirteen of $\mathrm{Cu}-\mathrm{Zr}$-Ti alloys in terms of critical cooling rate and fragility were evaluated by combining CALPHAD technique with kinetic approach. The driving forces for crystallization from the undercooled liquid alloys were calculated by using Turnbull and Thompson-Spaepen (TS) Gibbs free energy approximate equations, respectively. As shown in Fig. 7, time-temperature-transformation (TTT) curves of these alloys were obtained with Davies-Uhlmann kinetic equations based on classical nucleation theory. With Turnbull and TS equations, the critical cooling rates are calculated to be in the range of 9.78 $\times 10^{3}-8.23 \times 10^{5} \mathrm{~K} / \mathrm{s}$ and $4.32 \times 10^{2}-3.63 \times 10^{4} \mathrm{~K} / \mathrm{s}$, respectively, for $\mathrm{Cu}-\mathrm{Zr}$ alloys, and $1.38 \times 10^{2}$ $7.34 \times 10^{5} \mathrm{~K} / \mathrm{s}$ and $0.64-1.36 \times 10^{4} \mathrm{~K} / \mathrm{s}$, respectively, for $\mathrm{Cu}-\mathrm{Zr}-\mathrm{Ti}$ alloys (Ge, et al., 2008).
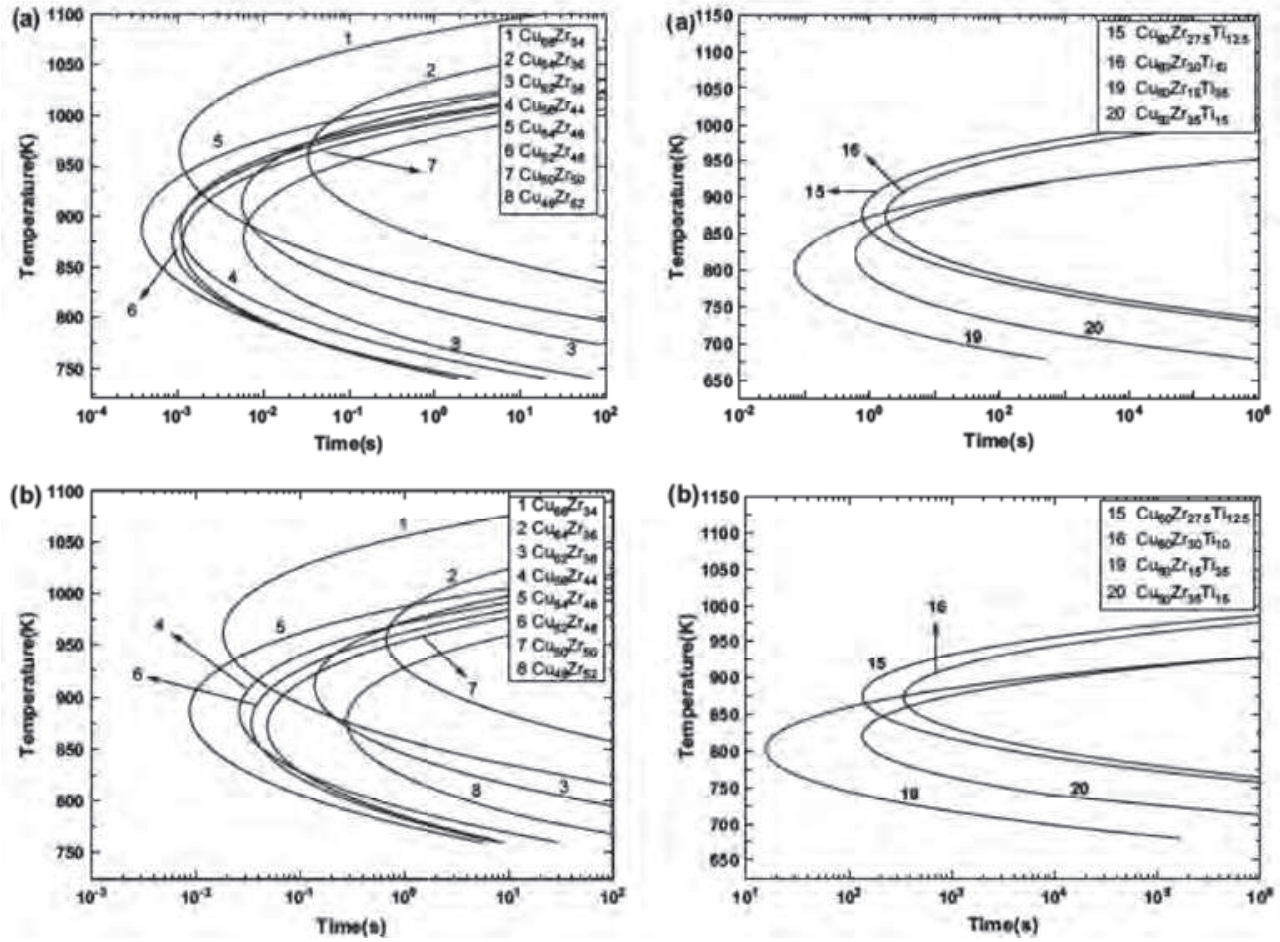

Fig. 7. Calculated TTT curve of Cu-Zr (left) and Cu-Zr-Ti (right) alloys by (a) Turnbull model and (b) TS model (from Ref. Ge, et al., 2008). 
Based on topological, kinetic and thermodynamic considerations, Yang et al. (Yang, et al., 2010) have discussed the existence of the multiple maxima in GFA in a single eutectic system in $\mathrm{Al}-\mathrm{Zr}-\mathrm{Ni}$ system. It is apparent that, when taken alone, none of the factors seemed to be able to fully explain this phenomenon we have observed. It is suggested that glass formation is an intricate balance of kinetic, thermodynamic and also topological factors. Perhaps in good glass formers, all factors could come to a consensus at one composition or one compositional zone, where the best glass former(s) are located. However, for marginal glass formers like Al-based alloys, each of these factors could point to a different alloy composition, where conditions are best suited for glass formation.

Recently, Considering chemical short-range ordering and metastability of undercooled melts, Zhu and co-workers have applied a simplified quasi-kinetic approach in order to predict the GFR in binary Al-rare earth (Zhu, et al., 2004) and Al-based Al-Gd-Ni(Fe) ternary system (Zhu, et al., 2004), using CALPHAD databases. They derived the derived an expression for the reduced time $t^{\prime}=t / t_{\min }$ for the formation of a minimal quantity of crystalline solid, where $t$ represents the composition-dependent time needed for the transformation and $t_{\min }$ the minimum transformation time at a certain optimum composition:

$$
t^{\prime} \approx\left(\frac{\exp \left(\Delta G^{*} / k T\right)}{\left[1-\exp \left(-\Delta G_{m} / R T\right)\right]^{3}}\right)^{1 / 4}
$$

This formula is in fact equivalent to Eqs. (10) to (23), except that the effect of parameters related to atomic transport is neglected. The calculated reduced times for various solid crystalline phases are then used to predict the GFR, i.e. the region of the composition space where these times are higher. A qualitative satisfactory agreement can be observed (Zhu, et al., 2004). The ability to predict the GFR of candidate metallic glass systems indicates a simple but effective approach for reducing reliance on extensive experimental trial and error in the search for new metallic glass systems (Zhu, et al., 2004).

\section{Conclusion}

Search for new bulk metallic glasses (BMGs) system or composition by predicting the GFA of an alloy system is of interesting and theoretical and practical significance. In this chapter, the progress on the calculation or predication the glass forming ability by thermodynamics approach or a combined thermodynamics and kinetics approach have been reviewed. It is found that a good agreement between the predicated glass forming ability and those experimentally observed has been obtained. It is indicated that the thermodynamic approach developed in the literature has proved useful to predict the glass forming ability of a number of alloys system. It has revealed that the combined thermodynamics and kinetics approach has the advantage to predict the glass forming ability of the multicomponent alloys using the reliable database of binary system assessed by CALPHAD method. It has been accepted that the thermodynamic approach and/or the combined thermodynamic and kinetic approach are effective ways for the prediction of the GFA of metallic glass alloys.

\section{Acknowledgment}

The financial support from the National Natural Science Foundation of China (NSFC) (Grant No. 50861006) and the Natural Science Foundation of Guangxi (Grant No. 0991002Z, 2011GXNSFC018002) are greatly acknowledged. 


\section{References}

Abe, T.; Shimono M.; Ode, M. \& Onodera, H. (2006). Thermodynamic modeling of the undercooled liquid in the $\mathrm{Cu}-\mathrm{Zr}$ system. Acta Materialia, Vol. 54, No. 4, (February 2006), pp. 909-915, ISSN 1359-6454

Bakker, H. (1988). Enthalpies in Alloys: Miedema's Semi-Empirical Model. Trans Tech, ISBN 978-087-8497-83-6, Uetikon-Zurich, Switzerland

Basu, J. ; Murty, B. S \& Ranganathan, S. (2008). Glass forming ability: Miedema approach to $(\mathrm{Zr}, \mathrm{Ti}, \mathrm{Hf})-(\mathrm{Cu}, \mathrm{Ni})$ binary and ternary alloys. Journal of Alloys and Compounds. Vol. 465, No. 1/2, (October 2008), pp. 163-172, ISSN 0925-8388

Battezzati, L.; Baricco, M.; Riontino, G. \& Soletta, I. (1990). Thermodynamic evaluation of the $\mathrm{Cu}$-Ti system in view of solid state amorphization reactions. Journal de Physique Colloques. Vol, 51, No, C4, (1990), pp. 79- 85, ISSN 0449-1947

Bhatt, J.; Jiang, W.; Xia, J.; Wang, Q. Chuang, D. \& Murty, B.S. (2007). Optimization of bulk metallic glass forming compositions in $\mathrm{Zr}-\mathrm{Cu}-\mathrm{Al}$ system by thermodynamic modeling. Intermetallics, Vol. 15, No. 5/6, (May/June 2007), pp. 716-721, ISSN 0966-9795

Bo, H.; Wang J.; Jin, S.; Qi, H. Y.; Yuan, X. L.; Liu L. B. \& Jin, Z.P. (2010). Thermodynamic analysis of the Al-Cu-Zr bulk metallic glass system. Intermetallics, Vol. 18, No. 12, (December 2010), pp. 2322-2327, ISSN 0966-9795

Boom, R. ; De Boer, M. R. \& Miedema, A. R. (1976). On the heat of mixing of liquid alloys. Journal of Less-Common Metetals, Vol. 45, No. 2, (March 1976), pp. 237-245, ISSN 0925-8388

Boettinger, W.J. \& Perepezko, J.H. (1993) in: Rapidly Solidified Alloys, Liebermann, H. H., (Ed.), Dekker M., p. 17, ISBN 978- 082-4789-51-2, New York,

Clavaguera-Mora, M.T. (1995). Glass materials: thermodynamic and kinetic quantities. Journal of Alloys and Compounds, Vol. 220, No. 1/2, (April 1995), pp. 197-205, ISSN 0925-8388

Cocco, G.; Soletta, I.; Battezzati, L.; Baricco, M. \& Enzo, S. (1990). Mechanical alloying of the Al-Ti system. Philosophical Magazine B, Vol. 61, No. 4, (April 1990), pp. 473-479, ISSN 1364-2812

Coehoorn, R.; Van der Kolk, G. J. ; Van den Broek, J. J. ; Minemura, T. \& Miedema, A. R. (1988). Thermodynamics of the stability of amorphous alloys of two transition metals. Journal of Less-Common Metetals, Vol. 140, No. 1/2, (June 1988), pp. 307-316, ISSN 0925-8388

Chen, Q.J.; Shen, J.; Fan H.B. ; Sun, J.F. ; Huang, Y.J. \& Mccartney, D.G. (2005). Glass-forming ability of an Iron-based alloy enhanced by Co addition and evaluated by a new criterion. Chinese Physics Letters, Vol. 22, No.7, (July 2005), pp.1736-1738, ISSN 0256-307X

Choi,Y. H. ; Busch, R. \& Johnson, W. L. (1998). The effect of silicon on the glass forming ability of the $\mathrm{Cu}_{47} \mathrm{Ti}_{34} \mathrm{Zr}_{11} \mathrm{Ni}_{8}$ bulk metallic glass forming alloy during processing of composites. Journal of Applied Physics, Vol. 83, No. 12, (June 1998), pp. 7993-7997. ISSN 0021-8979

Delamare, J. ; Lemarchand, D. \& Vigier P. (1994), Structural investigation of the metastable compound A1 in an as-cast Fe---Nd eutectic alloy. Journal of Alloys and Compouds, Vol. 216, No. 2, (January 1994), pp. 273-280, ISSN 0925-8388

De Boer, F. R. ; Boom, R. ; Mattens, W. C. M ; Miedema, A. R. \& Niessen, A. K. (1988). Cohesion in Metals: Transition Metals Alloys. North-Holland, ISBN 978-044-487098-8, Amsterdam, The Netherlands 
Eshelby, J. D. (1954). Distortion of a Crystal by Point Imperfections. Journal of Applied Physics, Vol. 25, No. 2, (February 1954), pp. 255-261. ISSN 0021-8979

Eshelby, J. D. (1956), The continuum theory of lattice defects. Solid State Physics : Advances in Research and Applications. Frederick Seitz and David Turnbull, (Ed.), Vol. 3, (1956), pp. 79-144, Elsevier, ISBN 978-0-12-374292-6, Amsterdam, the Netherlands

Friedel, J. (1954). Electronic structure of primary solid solutions in metals. Advances in Physics, Vol. 3, No. 12, (October 1954), pp. 446-507, ISSN 0001-8732

Fan, G. J.; Choo, H. \& Liaw, P. K. (2007). A new criterion for the glass-forming ability of liquids. Journal of Non-Crystalline Solids, Vol. 353, No.1, (January 2007), pp. 102-107, ISSN 0022-3093

Gao, M. C.; Hackenberg, R.E. \& Shiflet, G.J. (2003). Journal of Alloys and Compounds, Vol. 353, No. 1/2, (April 2003), pp. 114-123, ISSN 0925-8388

Ge, L.; Hui, X.; Wang, E.R.; Chen, G.L.; Arroyave, R. \& Liu, Z.K. (2008). Prediction of the glass forming ability in $\mathrm{Cu}-\mathrm{Zr}$ binary and $\mathrm{Cu}-\mathrm{Zr}$-Ti ternary alloys. Intermetallics, Vol. 16, No. 1, (January 2008), pp. 27-33, ISSN 0966-9795

Guo, F. Q.; Poon, S.J. \& Shiflet, G.J. (2000). Investigation of glass formability in Al-based multinary alloys. Scripta Materialia, Vol. 43, No. 12, (November 2000), pp. 10891095, ISSN 1359-6462

Guo, F. Q.; Poon, S. J. \& Shiflet, G. J. (2000), Glass formability in Al-based multinary alloys, Materials Science Forum, Vol. 331-337, ( 2000), pp. 31-42, ISSN 1662-9752

Guo, S. \& Liu, C.T. (2010). New glass forming ability criterion derived from cooling consideration. Intermetallics, Vol.18, No. 11, (November 2010) pp. 2065-2068, ISSN 0966-9795

Hackenberg, R. E.; Gao, M. C.; Kaufman, L. \& Shiflet, G.J. (2002). Thermodynamics and phase equilibria of the Al-Fe-Gd metallic glass-forming system. Acta Materialia, Vol. 50, No. 9, (May 2002), pp. 2245-2258, ISSN 1359-6454

He, Y.; Poon, S. J. \& Shiflet, G. J. (1988). Synthesis and properties of metallic that contain aluminum. Science, Vol. 241, No. 4873, (September 1988), pp. 1640-1642. ISSN 0036-8075

Inoue, A.; Zhang, T. \& Masumoto, T. (1993). Glass-forming ability of alloys. Journal of NonCrystalline Solids, Vol.156-158, No. 2, (May 1993), pp.473-480, ISSN 0022-3093

Inoue, A.; Zhang, T. \& Takeuchi, A. (1998). Ferrous and Nonferrous Bulk Amorphous Alloys, Materials Science Forum, Vol. 269-272, (1998), pp. 855-864, ISSN 0255-5476

Inoue, A. ; Zhang, W. ; Zhang, T. \& Kurosaka K. (2001). High-strength Cu-based bulk glassy alloys in $\mathrm{Cu}-\mathrm{Zr}-\mathrm{Ti}$ and $\mathrm{Cu}-\mathrm{Hf}-\mathrm{Ti}$ ternary systems, Acta Materialia, Vol. 49, No.14, (August 2001), pp. 2645-2652, ISSN 1359-6454

Inoue, A.; Ohtera, K.; Tsai, A. P. \& Masumoto, T. (1988). Aluminum-based amorphous alloys with tensile strength above $980 \mathrm{MPa}(100 \mathrm{~kg} / \mathrm{mm} 2)$. Japanese Journal of Applied Physics, Vol. 27, No. 4, (April 1988), pp. L479-L482, ISSN 0021-4922

Inoue, A. (1998). Amorphous, nanoquasicrystalline and nanocrystalline alloys in Al-based systems. Progress in Materials Science, Vol. 43, No. 5, (December 1998), pp. 365-520, ISSN 0079-6425

Ji, X.L.; \& Pan, N.Y. (2009). A thermodynamic approach to assess glass-forming ability of bulk metallic glasses. Transaction of Nonferrous Metals Society of China, Vol. 19, No. 5 (October 2009), pp.1271- 1279, ISSN 1003-6326

Ji, X.L.; Pan, Y. \& Ni, F. (2009). A thermodynamic criterion for predicting glass-forming ability in binary metallic glasses. Materials and Design, Vol. 30, No. 3, (March 2009), pp. 842-845, ISSN 0261-3069

Jonson, W. L. (1999). Bulk glass-forming metallic alloys: science and technology. MRS Bulletin. Vol. 24, No. 10, (October 1999), pp. 42-56, ISSN 0883-7694 
Kaufman, L. \& Bernstein H. (1970). Computer calculation of phase diagrams. Academic Press; ISBN 978-1-84569-215-5, NY, USA

Kang, D. H. \& Jung, I. H. (2010). Critical thermodynamic evaluation and optimization of the $\mathrm{Ag}-\mathrm{Zr}, \mathrm{Cu}-\mathrm{Zr}$ and $\mathrm{Ag}-\mathrm{Cu}-\mathrm{Zr}$ systems and its applications to amorphous $\mathrm{Cu}-\mathrm{Zr}-$ Ag alloys. Intermetallics, Vol. 18, No. 5, (May 2010), pp. 815-833, ISSN 0966-9795

Kawazoe, Y.; Masumoto, T.; Suzuki, K.; Inoue, A.; Tsai, A. P.; Yu, J. Z.; Aihara, J.T. \& Nakanomyo, T. (1997). Nonequilibrium phase diagrams of ternary amorphous alloys. In: Landolt- Bönstein, New Series III: Condensed Matter, Y. Kawazoe, J. Z. Yu, A. P. Tsai \& T. Masumoto, (Ed.), vol. 37A, p. 112, ISBN 978-3-540-65664-7

Kim, D.; Lee B. J. \& Kim, N. J. (2004). Thermodynamic approach for predicting the glass forming ability of amorphous alloys. Intermetallics. Vol. 12, No. 10-11, (OctoberNovember 2004), pp. 1103-1107, ISSN 0966-9795

Kim, D. ; Lee, B. J. \& Kim, N. J. (2005). Prediction of composition dependency of glass forming ability of $\mathrm{Mg}-\mathrm{Cu}-\mathrm{Y}$ alloys by thermodynamic approach. Scripta Materialia, Vol. 52, (2005), pp. 969-972, ISSN 1359-6462

Kim, Y. K.; Soh, J. R.; Kim H. S. \& Lee, H. M. (1998). Thermodynamic prediction of glass forming range in Al-Mg-REM ternary system. CALPHAD. Vol. 22, No. 2, (June 1998). pp. 221-2301, ISSN 0364-5916

Kumar, K. C. H.; Ansara, I.; Wollants, \& P. Delaey, L. (1996). Thermodynamic optimisation of the Cu-Ti system. Zeitschrift für Metallkunde. Vol. 87, No. 8, (August 1996), pp. 666-672, ISSN 0044-093

Klement, W. ; Willens, R.H. \& Duwez, P. (1960). Noncrystalline structure in solidified goldsilicon alloys. Nature, Vol.187, No.4740, (September 1960), pp. 869-870, ISSN 0028-0836

Lin, X. H. \& Johnson, W.L. (1995). Formation of Ti-Zr-Cu-Ni bulk metallic glasses. Journal of Applied Physics, Vol. 78, No. 11, (December 1995), pp. 6514-6519. ISSN 0021-8979

Lu, Z.P. \& Liu, C.T. (2002). A new glass-forming ability criterion for bulk metallic glasses. Acta Materialia, Vol.50, No.13, (August 2002), pp.3501-3512, ISSN 1359-6454

Liu, X.J.; Hui, X.D. \& Chen, G.L. (2008). Thermodynamic calculation and experimental investigation of glass formation in Zr-Ni-Ti alloy system. Intermetallics, Vol. 16, No. 2, (February 2008), pp. 262-266, ISSN 0966-9795

Miedema, A. R. ; Boom, R. \& De Boer, M. R. (1975). On the heat of formation of solid alloys. Journal of Less-Common Metals, Vol. 41, No. 2 (July 1975), pp. 283-298, ISSN 09258388

Mishra, R. K. \&. Dubey S. (2009). Glass forming ability of materials: A thermodynamic approach. Journal of Non-Crystalline Solids. Vol. 355, No. 45-47 (November 2009), pp. 2199-2204, ISSN 0022-3093

Murty, B. S.; Ranganathan, S. \& Rao, M. M. (1992). Solid state amorphization in binary Ti-Ni, Ti-Cu and ternary Ti---Ni---Cu system by mechanical alloying. Materials Science and Engeering A, Vol. 149, No. 2, (January 1992), pp. 231-240, ISSN 0921-5093

Nagarajan, R. \& Ranganathan, S. (1994). A study of the glass-forming range in the ternary Ti-Ni-Al system by mechanical alloying. Materials Science and Engeering A, Vol, 179/180, No. 1, (May 1994), pp. 168-172, ISSN $0921-5093$

Niessen, A. K. ; Boer, F.R. de ; Boom, R. ; Chatel, P.F. de ; Mattern, W.C.M. \& Miedema, A.R. Model predictions for the enthalpy of formation of transition metal alloys II. CALPHAD, Vol. 7, No. 1, (Januay-March 1983), pp. 51-70, ISSN 0364-5916

Oliveira, M. F.; Aliaga, L.C.; Bolfarini, R.C. ; Botta, W.J. \& Kiminami, C.S. (2008). Thermodynamic and topological instability approaches for forecasting glassforming ability in the ternary Al-Ni-Y system. Journal of Alloys and Compounds, Vol. 464, No. 1/2, (September 2008), pp. 118-121, ISSN 0925-8388 
Porter, D. A. \& Easterling K. E. (1992). Phase transformation in metals and alloys. Chapman \& Hall, ISBN 978- 074-8757-41-1 , London, UK

Palumbo, M.; Cacciamani, G.; Bosco, E. \& Baricco, M. (2001). Thermodynamic analysis of glass formation in Fe-B system, CALPHAD, Vol. 25, No. 4, (December, 2001), pp. 625-637. ISSN 0364-5916

Palumbo, M. \& Battezzati, L. (2008). Thermodynamics and kinetics of metallic amorphous phases in the framework of the CALPHAD approach. CALPHA, Vol. 32, No. 2, (June 2008), pp. 295-314, ISSN 0364-5916

Rao, B. S.; Bhatt, J. \& Murty, B. S. (2007). Identification of compositions with highest glass forming ability in multicomponent systems by thermodynamic and topological approaches. Materials Science and Engineering A, Vol. 449-451, No. 1, (March 2007), pp. 211-214, ISSN 0921-5093

Ramachandrarao, P.; Cantor, B. \& Cahn, R.W. (1977). Free volume theories of the glass transition and the special case of metallic glasses. Journal of Materials Science, Vol. 12, No. 12, (December 1977), pp. 2488-2502, ISSN 0022-2461

Saunders, N. \& Miodownik, A. P. (1988). Evaluation of glass forming ability in binary and ternary metallic alloy systems - an application of thermodynamic phase diagram calculation. Materials Science and Technology, Vol. 4, No. 9, (September 1988), pp. 768-777, ISSN 0267-0836

Saunders, N. \& Miodownik, A.P. (1986). Thermodynamic aspects of amorphous phase formation. Journal of Materials Research, Vol. 1, No. 1, (January 1986), pp. 38-46. ISSN 0884-2914

Saunders, N. \& Miodownik, A.P. (1985). The use of free energy vs composition curves in the prediction of phase formation in codeposited alloy thin films. CALPHAD, Vol. 9, No. 3, (September 1985), pp. 283-290, ISSN 0364-5916

Schwarz, R. B.; Nash, P. \& Turnbull, D. (1987). The use of thermodynamic models in the prediction of the glass-forming range of binary alloys. Journal of Materials Research. Vol. 2, No. 4, (July 1987), pp. 456-460, ISSN 0884-2914

Shao, G.; Lu, B.; Liu, Y.Q. \& Tsakiropoulos P. (2005). Glass forming ability of multicomponent metallic systems. Intermetallics, Vol. 13, No. 3/4, (March/April 2005), pp. 409-414, ISSN 0966-9795

Shim, J. H.; Chung, H.-J. \& Lee, D. N. (1999). Calculation of phase equilibria and evaluation of glass-forming ability of Ni-P alloys. Journal of Alloys and Compounds, Vol. 282, No. 1/2, (January 1999), pp. 145-181, ISSN 0925-8388

Simozar, S. \& Alonso, J.A. ; On the Factors Controlling Glass Forming Ability of Metallic Alloys Formed by Fast Liquid Quenching. Physica Status Solidi (a), Vol. 81, No.1, (January 1984), pp. 55-61, ISSN 1862-6319

Sun, S.P.; Yi, D. Q.; Liu, H.Q.; Zang B. \&Jiang, Y. (2010). Calculation of glass forming ranges in Al-Ni-RE (Ce, La, Y) ternary alloys and their sub-binaries based on Miedema's model. Journal of Alloys and Compounds, Vol. 506, No. 1, (September, 2010) 377-387, ISSN 0925-8388

Takeuchi, A. \& Inoue, A. (2000). Calculations of Mixing Enthalpy and Mismatch Entropy for Ternary Amorphous Alloys. Materials Transactions JIM, Vol. 41, No. 11, (November 2000), pp. 1372-1378, ISSN 0916-1821

Takeuchi, A. \& Inoue, A. (2001). Calculations of Amorphous-Forming Composition Range for Ternary Alloy Systems and Analyses of Stabilization of Amorphous Phase and Amorphous-Forming Ability. Materials Transactions JIM, Vol, 42, No. 7 (July 2001) 1435-1444, ISSN 0916-1821 
Takeuchi, A. \& Inoue, A. (2001). Thermodinamic and kinetic analyses of formation of amorphous and nanocrystalline alloys with the aid of computer and database. Journal of Optoelectronics and Advanced Materials, Vol, 6, No. 2, (June 2004), pp. 533540, ISSN 1454-4164

Tang, C. Y.; Du, Y.; Wang, J.; Zhou, H. Y.; Zhang, L.J.; Zheng, F.; Lee, J. \& Yao, Q. (2010). Correlation between the thermodynamics and the glass forming ability in the AlCe-Ni system, Intermetallics, Vol. 18, No. 5, (May 2010), pp. 900- 906, ISSN 0966-9795

Tokunaga, T.; Ohtani, H. \& Hasebe, M. (2004). Thermodynamic evaluation of the phase equilibria and glass-forming ability of the Fe-Si-B system. CALPHAD, Vol. 28, No. 4, (December 2004), pp. 354-362. ISSN 0364-5916

Turnbull, D. (1950). Formation of crystal nuclei in liquid metals. Journal of Applied Physics, Vol. 21, No. 11, (November 1950), pp. 1022-1028, ISSN 0021-8979

Turnbull, D.(1969). Under what conditions can a glass be formed? Contemporary Physics, Vol.10, No. 5, (October 1969), pp.473-488, ISSN 0010-7514

Uhlmann, D.R. (1972). A kinetic treatment of glass formation. Journal of Non-Crystalline Solids, Vol. 7, No. 4 (May 1972), pp.337-348, ISSN 0022-3093

Van der Kolk, G. J. ; Miedema A. R. \& Niessen, A. K. (1988). On the composition range of amorphous binary transition metal alloys. Journal of Less-Common Metetals, Vol. 145, No. 1/2, (December 1988), pp. 1-17, ISSN 0925-8388

Wang, T.L.; Wang, W.C.; Li, J.H. \& Liu, B.X. (2010). Glass formation of the Fe-Hf system studied by thermodynamic calculation and ion beam mixing. Journal of Alloys and Compounds, Vol. 493, No 1/2. (March 2010), pp. 154-157, ISSN 0925-8388

Wang, T.L.; Li, J.H. \& Liu, B.X. (2009). Proposed thermodynamic method to predict the glass formation of the ternary transition metal systems. Physical Chemistry Chemical Physics, Vol. 11, No, 14, (February 2009), pp. 2371-2373, ISSN 1463-9076

Wang, T.L. \& Liu B.X. (2009). Glass forming ability of the Fe-Zr-Cu system studied by thermodynamic calculation and ion beam mixing. Journal of Alloys and Compounds, Vol. 481, No. 1/2, (July 2009), pp. 156-160, ISSN 0925-8388

Xia, L.; Fang S. S.; Wang, Q.; Dong, Y. D. \& Liu, C.T. (2006). Thermodynamic modeling of glass formation in metallic glasses. Applied Physic Letters, Vol. 88, No. 17, (April 2006), pp. 171905 -171905-3, ISSN 0003-6951

Xia, L.; Li, W. H.; Fang, S. S.; Wei B. C. \& Dong, Y. D. (2006). Binary Ni-Nb bulk metallic glasses. Journal of Applied Physics, Vol. 99, No. 2, (January 2006), pp. 026103-1-3, ISSN 0021-8979

Yang, H.; Lim, K.Y. \& Li Y. (2010). Multiple maxima in glass-forming ability in Al-Zr-Ni system. Journal of Alloys and Compounds, Vol. 489, No.1, (January 2010), pp. 183-187, ISSN 0925-8388

Yuan, Z.Z.; Bao, S.L. ; Lu, Y.; Zhang, D.P. \& Yao, L. (2008). A new criterion for evaluating the glass-forming ability of bulk glass forming alloys. Journal of Alloys and Compouds, Vol. 459, No. 1/2, ( July 2008), pp. 251-260, ISSN 0925-8388

Zhu, A.; Shiflet, G. J. \& Miracle, D. B. (2004). Glass forming ranges of Al-rare earth metal alloys: thermodynamic and kinetic analysis. Scripta Materialia, Vol. 50, No. 7, (April 2004), pp. 987-991, ISSN 1359-6462

Zhu, A.; Poon, S. J. \& Shiflet, G. J. (2004). On glass formability of Al-Gd-Ni (Fe). Scripta Materialia, Vol. 50, No. 12, (June 2004), pp. 1451-1455, ISSN 1359-6462 


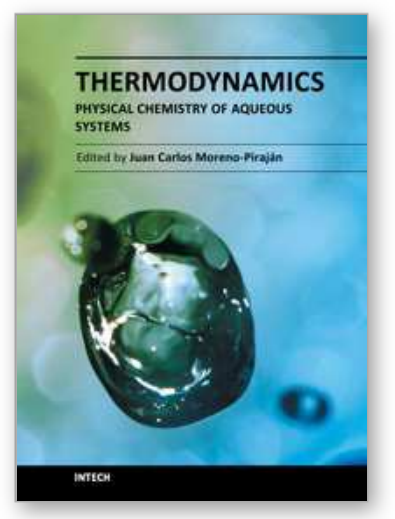

\author{
Thermodynamics - Physical Chemistry of Aqueous Systems \\ Edited by Dr. Juan Carlos Moreno Pirajễin
}

ISBN 978-953-307-979-0

Hard cover, 434 pages

Publisher InTech

Published online 15, September, 2011

Published in print edition September, 2011

Thermodynamics is one of the most exciting branches of physical chemistry which has greatly contributed to the modern science. Being concentrated on a wide range of applications of thermodynamics, this book gathers a series of contributions by the finest scientists in the world, gathered in an orderly manner. It can be used in post-graduate courses for students and as a reference book, as it is written in a language pleasing to the reader. It can also serve as a reference material for researchers to whom the thermodynamics is one of the area of interest.

\title{
How to reference
}

In order to correctly reference this scholarly work, feel free to copy and paste the following:

Chengying Tang and Huaiying Zhou (2011). Thermodynamics and the Glass Forming Ability of Alloys, Thermodynamics - Physical Chemistry of Aqueous Systems, Dr. Juan Carlos Moreno PirajÃ in (Ed.), ISBN: 978-953-307-979-0, InTech, Available from: http://www.intechopen.com/books/thermodynamics-physicalchemistry-of-aqueous-systems/thermodynamics-and-the-glass-forming-ability-of-alloys

\section{INTECH}

open science | open minds

\section{InTech Europe}

University Campus STeP Ri

Slavka Krautzeka 83/A

51000 Rijeka, Croatia

Phone: +385 (51) 770447

Fax: +385 (51) 686166

www.intechopen.com

\section{InTech China}

Unit 405, Office Block, Hotel Equatorial Shanghai

No.65, Yan An Road (West), Shanghai, 200040, China

中国上海市延安西路65号上海国际贵都大饭店办公楼405单元

Phone: +86-21-62489820

Fax: $+86-21-62489821$ 
(C) 2011 The Author(s). Licensee IntechOpen. This chapter is distributed under the terms of the Creative Commons Attribution-NonCommercialShareAlike-3.0 License, which permits use, distribution and reproduction for non-commercial purposes, provided the original is properly cited and derivative works building on this content are distributed under the same license. 